\title{
EL DISEÑO DE EXPERIENCIAS EN ROBÓTICA SOCIAL ASISTENCIAL PARA LA TERCERDA EDAD
}

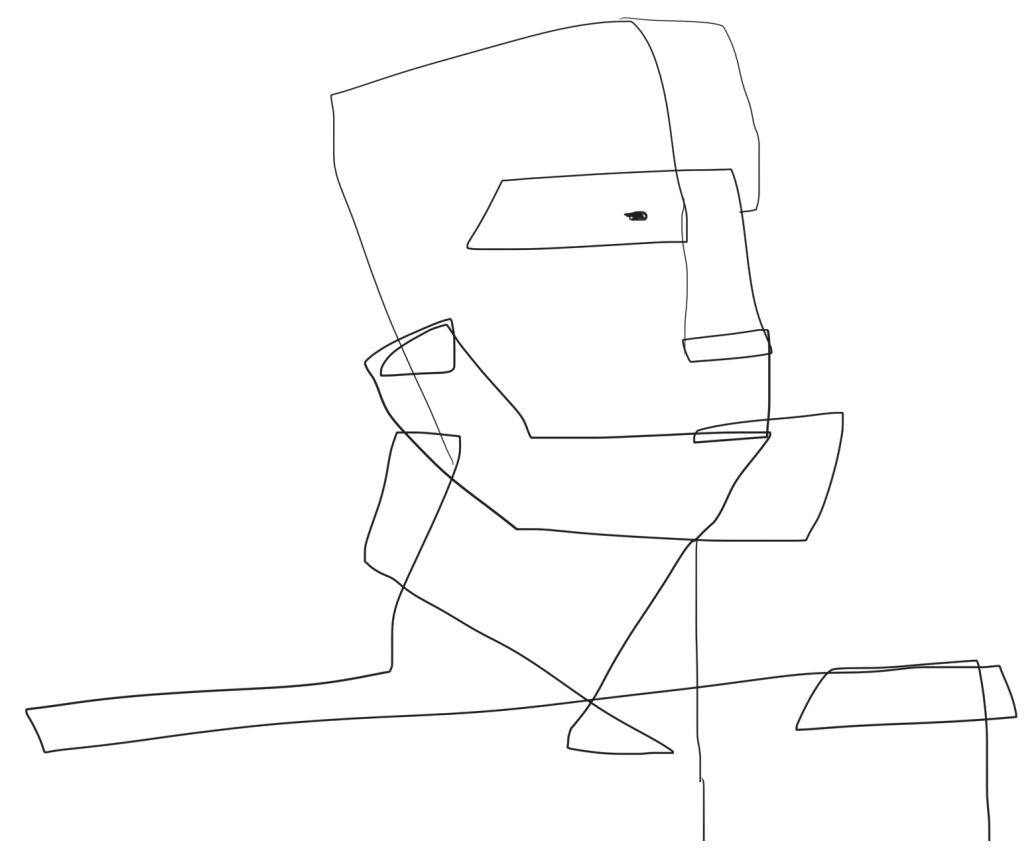

\author{
DESIGN OF EXPERIENCES IN SOCIAL \\ ASSISTANCE ROBOTIC FOR THE \\ ELDERLY \\ O DESENHO DE EXPERIENCIAS EM \\ ROBÓTICA SOCIAL ASSISTENCIAL \\ PARA A TERCEIRA IDADE
}

Por:

Andrés Reina Gutiérrez

Departamento de Diseño

Universidad del Valle

salomonreina@gmail.com

Resumen: El presente texto se deriva de la revisión del estado del arte del proyecto de tesis El diseño de experiencias en robótica social asistencial para la tercera edad:Análisis de la película Robot \& Frank, presentada para la obtención del título de Maestría en Filosofía de la Universidad del Valle. Esta revisión gira en torno a la articulación que existe entre el diseño de experiencias y la robótica social asistencial, desde una perspectiva sociofenomenológica. El diseño como actividad basada en la expectativa del emisor respecto a un receptor como sujeto de experiencias, mediante la formalización objetual, suscita grandes expectativas en el campo de la robótica social, un área clave de investigación de la inteligencia artificial, que se ha concentrado en el desarrollo de sistemas interactivos robóticos pensados para actuar en ciertas comunidades como apoyo a sus tareas cotidianas. Los grandes dilemas éticos que esto generará ya han comenzado a ser abordados filosófica y sociológicamente, pero, el enfoque de esta investigación no es el problema ético, sino el estético y se desarrolla sobre dos cuestionamientos: ¿Se puede considerar la robótica social otra manifestación del diseño de experiencias?, y ¿Cuáles son los criterios que debe cumplir el diseño de un robot (relación forma-función-uso) para potenciar los efectos de la experiencia estética del usuario?

Palabras Clave: Diseño de experiencias, Robótica social asistencial, Simulación de intersubjetividad, Comunicación, Lenguaje y estética. 


\begin{abstract}
This text derives from the review of the state of the art of the thesis "Design of experiences in social assistance robotic for the elderly": analysis of the movie Robot \& Frank, presented to obtain the Master's degree in Philosophy at the Universidad del Valle. This review is focused on the joint that exists between the design of experiences and the social assistance robotic, from a social phenomenological approach. The design as an activity based on sender's expectation with respect to a receiver as a subject of experiences, through the formalization of the object, arouses huge expectations in the field of social robotic, a key area of artificial intelligence research, that has been centered on the development of interactive robotic systems that are aimed at acting among certain communities as a support to their daily tasks. The most relevant ethical dilemma that this will trigger has already began to be philosophically and sociologically addressed. Nevertheless, this researcher's approach is not the ethical problem, but the aesthetic one, and it is developed based on two questions: Can social robotic be considered as another manifestation of design of experiences? And what are the criteria that have to be met by robotic design (shape-function-usage relationship) in order to power the effects of aesthetic customer experience?
\end{abstract}

Keywords: Design of Experiences, Social Assistance Robotic, Artificial Intelligence, Shape, Function, Usage, Intersubjective Simulation, Communication, Language and Aesthetic.

Resumo: Este texto deriva-se da revisão do estado da arte do projeto de tese "O desenho de experiências em robótica social assistencial para a terceira idade: Análise do filme Robot \& Frank”, apresentado para o título de Mestrado em Filosofia da Universidad del Valle. Esta revisão é em torno à articulação que existe entre o desenho de experiências e a robótica social assistencial, desde a perspectiva socio-fenomenológica. O desenho, como atividade baseada na expectativa do emissor ao respeito do recetor, por meio da formalização objetal, suscita grandes expectativas no campo da robótica social, uma área chave de pesquisa da inteligência artificial, que tem se concentrado no desenvolvimento de sistemas interativos robóticos visados para agir em certas comunidades como apoio à suas tarefas cotidianas. Os grandes dilemas éticos que esto gerará já têm começado a ser tratados no plano sociológico e filosófico. Porém, o foco desta pesquisa não é o problema ético, mas o estético e se desenvolve sobre duas questões: Pode-se considerar a robótica social como outra manifestação do desenho de experiências? E quais são os critérios que debe cumprir o desenho de um robô (relação forma-função-uso) para potenciar os efeitos da experiência estética do usuário?

Palavras-chave: Desenho de Experiências, Robótica social assistencial, Inteligência artificial, Forma, Uso, Simulação de intersubjetividade, Comunicação, Linguagem e Estética. 


\section{Introducción: La robótica social como diseño de experiencias}

El diseño, como actividad que posibilita la planificación y el desarrollo de objetos empleados en la cotidianidad, tiene diversos campos de énfasis y estudio, según los aspectos prácticos de función y uso sociales. Las categorías determinantes que fundamentan su clasificación por profesiones, son las que están relacionadas con el tipo de objeto diseñado, y establecen un corpus de estudio determinado. Por ejemplo, el diseño gráfico, se determina por la producción de mensajes en formatos bidimensionales, el diseño industrial, por la producción de objetos tridimensionales necesarios para la vida práctica, o el diseño textil y de modas, por las características del vestuario. También podemos establecer categorías de acuerdo con sus elementos funcionales, como el diseño de la información, el diseño de identidad o el diseño persuasivo; en los cuales se construyen mensajes linguísticos, icónicos o mixtos, con diversos propósitos de comunicación y expresión social.

Independientemente de los criterios categoriales que empleemos (que pueden provenir de las acciones comunicativas, de los medios empleados o de los resultados concretos), el diseño tiene un fundamento en su práctica que está determinado por el significado del término designio. La actividad de diseñar implica una fase de ideación y un proceso de concreción en resultados objetuales; una planificación que se traduce en un estado material; una proyección formal mental que se convertirá en un sistema de elementos dotados de forma física, perceptible sensorialmente por un observador. Así, la denominación diseño de experiencias (que proviene de una acepción propia del campo profesional de la disciplina en su acción comunicativa por medio de soportes físicos) es transversal a todas las clasificaciones, porque hace referencia a una expectativa experiencial del sujeto receptor. Las categorías de diseño han sido obtenidas tradicionalmente según los aspectos del proceso creativo y productivo o según los medios y soportes en los que se constituyen sus formas resultantes, pero desde el punto de vista del uso social, es apenas evidente que todo diseño es experiencial. Dicha cualidad alude a un conjunto de actos de conciencia que se producen en el momento en el que, como usuarios, nos relacionamos con objetos diseñados; sujetos de experiencias que actuamos sobre objetos artificiales. Así pues, todo diseño es experiencial: diseño de carteles, de audio-visuales, de productos de uso diario, de vestuario o de interiores. Esta virtud fundamental y determinante del diseño, es el punto de partida para indagar en un énfasis que suscita grandes interrogantes y expectativas comunes al diseño industrial y la ingeniería computacional: la robótica social.

La robótica social es una área supremamente amplia de investigación de la inteligencia artificial, que ha sido orientada a los sistemas interactivos robóticos que pretenden intervenir en ciertas comunidades sociales como apoyo a sus tareas cotidianas. Estos dispositivos automáticos son cada vez más comunes en estratos exclusivos, pertenecientes a sociedades con elevados niveles de desarrollo económico y tecnológico. Han sido diseñados, en mayor medida, con apariencia humanoide y zoomorfa, ostentando tres cualidades fundamentales: un desempeño funcional altamente sofisticado, una simulación ${ }^{1}$ afectiva verosímil y una adecuación formal eficaz. 
Al igual que el televisor, el automóvil o el computador, seremos testigos de cómo estas sofisticadas máquinas lograrán un enorme nivel de difusión y accesibilidad en la mayoría de las sociedades, a largo plazo. Los grandes dilemas éticos que esto generará ya han comenzado a ser abordados filosófica y sociológicamente, además de haber sido ampliamente explorados en relatos de ciencia ficción de la literatura y el cine desde mediados del siglo XX.

Pero el enfoque de esta investigación no es el problema ético, sino el estético. El punto de partida surge de dos cuestionamientos: ¿Se puede considerar la robótica social otra manifestación del diseño de experiencias?, y ¿Cuáles son los criterios que debe cumplir el diseño de un robot (relación forma-función-uso) para potenciar los efectos de la experiencia estética del usuario?.

A continuación, revisaré las dos nociones fundamentales (Robótica social/Diseño de experiencias) y argumentaré por qué el diseño de experiencias es una modalidad discursiva necesaria en los procesos de intervención de la robótica social. Una vez dado este primer paso, abordaré el problema del lenguaje como condición fundamental de la aparente intersubjetividad entre el usuario y el robot, bajo una perspectiva fenomenológica.

\section{a. LA ROBÓTICA SOCIAL ASISTENCIAL PARA PERSONAS DE LATERCERA EDAD}

Los avances tecnológicos que se han logrado hasta el momento en el campo de la robótica social asistencial, han permitido desarrollar máquinas “inteligentes” para asistir a personas con algún tipo de discapacidad cognitiva, en sus distintas manifestaciones (como enfermos de Alzheimer o ancianos con reducciones físicas y cognitivas). Hoy en día, ASIMO, uno de los robots más sofisticados que se utilizan en el campo financiero de Tokio, es capaz de recibir, guiar y atender clientes eficazmente, mediante acciones tremendamente complejas (desplazamiento o agarre de objetos) y la capacidad de establecer una conversación fluida con ellos. Sin embargo, en el área de la asistencia social aún no hay resultados apropiados, debido a las grandes responsabilidades que implica la intervención robótica en el sector de la salud.

La robótica social es la rama de la robótica, que se encarga de desarrollar servicios de atención artificial personalizada a través de la implementación de robots o máquinas autónomas que pueden adecuarse a dinámicas de "inteligencia social”; es decir, operadores autómatas que interactúan de manera sencilla y eficaz con seres humanos en actividades sociales cotidianas. El asunto de la sencillez es clave, pues es el fundamento de la relación operacional de una máquina en la que el usuario no requiere alguna destreza o competencia especial para utilizarla. A diferencia de un computador o un automóvil, un robot social, para ser operado sólo requiere las expresiones verbales y gestuales del usuario e interactúa con éste gracias a un complejo sistema de controladores que, mediante receptores visuales y sensores, "capta e interpreta" sus posibles requerimientos. Al estudio de estos mecanismos de "sencillez" operacional se le ha denominado usabilidad (facilidad de uso) y se apoya principalmente en la interfaz de usuario. 
En un computador, la interfaz, soportada en hardware y software, es el recurso instrumental mediante el cual el dispositivo puede ser operado, como el teclado, el mouse, el monitor y la imagen digital (que en algunos casos permite la manipulación directamente en la pantalla, como las tablas digitales y celulares sofisticados). La utilización de un robot se produce, podríamos decir, gracias a una "interfaz audio-visual", pues el usuario no requiere oprimir botones ni escribir en un teclado, sino hablarle a la máquina y expresarle sus preguntas o solicitudes. La interfaz está conformada por su apariencia general y los intrincados dispositivos de interacción y comunicación. El robot recibe la información linguística y visual, la procesa y responde de forma clara, sencilla y natural con base en expresiones verbales y no verbales, siguiendo comportamientos, patrones y normas sociales. Estos espectaculares androides ya son capaces de relacionarse en modos avanzados de interacción, mediante un diseño y una programación previos que les permiten adaptarse al comportamiento del usuario.

La investigación en robótica social asistencial se preocupa por la compleja relación que existe entre un usuario y un robot en ambientes cotidianos. El usuario habita ciertos escenarios del mundo de la vida cotidiana, en los cuales manifiesta necesidades de diversa índole: comunicación, seguridad, bienestar o entretenimiento, entre otros. Estas condiciones suponen que el robot, que va a ser insertado en el mundo del paciente, sea de una elevada intromisión; absolutamente invasivo del espacio íntimo y privado del usuario (Salichs, Salichs, Encinar, Castro-González y Malfaz, 2014). Esta situación, de entrada, marca el principal desafío a los ingenieros y diseñadores en robótica social asistencial para pacientes de la tercera edad: ¿Cómo intervenir la cotidianidad de un anciano que padece alguna disfunción cognitiva (como el Alzheimer o la demencia senil) para que el apoyo de un robot le resulte aceptable y eficaz?
Adicionalmente, existen dos agravantes que dificultan el proceso de aceptación de los robots asistenciales. Por una parte, existe un recelo generalizado respecto a su implementación en la cotidianidad, que está basado en el antiguo temor a la sustitución del ser humano por las máquinas. Segundo, es evidente la preferencia de los pacientes por la asistencia y compañía de personas conocidas. Sin embargo, estas circunstancias no tienen un fundamento sólido, pues el siglo XX ha sido testigo de la continua armonización entre humanos y máquinas de todo tipo y en diversas situaciones; respecto a lo segundo, no sólo la tendencia de una familia o un cuidador es aceptar la posibilidad de este tipo de apoyo tecnológico (dado que la máquina se asume como complemento, pues es una labor extenuante para una persona tanto en un nivel físico como sicológico), sino que el anciano tiende a preferir la soledad a una compañía indeseada o incómoda. En ese sentido, el robot viene a convertirse en el status primario de objeto, que no afecta drásticamente la sensación de soledad del anciano, pues lo percibe, inicialmente, como un electrodoméstico más.

Desde el punto de vista formal (la característica predominante para el diseño de la interfaz), se han desarrollado dos grandes categorías de robots sociales que han mostrado un acertado nivel de eficacia en los experimentos realizados hasta el momento: los robots humanoides y los robots zoomorfos. En ambos casos, la estrategia es generar en el paciente una relación de intercambio, basada en un esquema emocional tipo Amo - Mascota. El anciano obtiene la sensación de control y dominio en el uso de la máquina, a la cual le atribuye un estatus de indefensión, pero sin restarle su gran importancia como compañía. De igual manera, el robot actúa con el paciente, asistiéndolo y haciéndole más llevadera la enfermedad, al cumplir eficazmente objetivos como reducir el stress, mejorar el bienestar físico e incentivar el deseo de socialización del paciente. Esta categoría proporciona beneficios similares a 
los que produce el trabajo de terapia con animales domésticos, pero con la gran ventaja de que los robots zoomorfos no requieren el cuidado y atención de una verdadera mascota. Sin embargo, los robots humanoides, por razones formales y funcionales, han sido los más pertinentes para lograr un óptimo desempeño asistencial, pues debido a su inspiración antropomórfica, posibilitan de mejor manera las funciones de evocación de costumbres, comportamiento, interacción y sociabilidad. Algunas tareas concretas que pueden realizar los robots sociales humanoides son: monitoreo permanente del usuario, estimulación física y cognitiva, asistencia física, coordinación de actividades generales, entretenimiento y compañía (Salichs et al., 2014).

El diagnóstico de necesidades de enfermos de Alzheimer o demencia senil en determinados contextos, genera los lineamientos de trabajo de los expertos en ingeniería computacional, ingeniería mecánica, ingeniería electrónica y diseño industrial (principalmente estas cuatro profesiones), quienes deben elaborar un listado de requerimientos obligatorios y deseados, para los cuales se establecen los objetivos y funciones correspondientes. Este proceso de desarrollo interdisciplinario, se aborda bajo tres grandes etapas: Diseño, Intervención y Evaluación.

\section{El proceso de diseño en la robótica social asistencial}

Como ya hemos visto, a diferencia de otras áreas de enfoque de la robótica (como la encargada de desarrollar e implementar robots industriales), el proceso de diseño en la robótica social es particularmente complejo porque el desempeño (acción) de la máquina (su función) no es de mayor importancia a su apariencia (la forma). Ambas consideraciones son fundamentales, pues el robot tiene que realizar apropiadamente tareas prácticas y, también, debe resultar agradable. Por otra parte, adicionalmente al propósito de ser eficaz, tanto en el aspecto práctico como estético, se espera que el androide genere en el usuario un fuerte sentimiento de confianza, como una de las significatividades ${ }^{2}$ más necesarias (Schutz, 2009). Este proceso en tres pasos (función práctica, estética y simbólica), tan evidente y fundamental en la práctica del diseño y todas sus especialidades (Löbach, 1976), sintetiza el proceso interdisciplinario de ideación, proyección y ejecución de un robot social.

Para desarrollar minuciosamente la relación entre diseño y robótica social, comenzaré por presentar la siguiente premisa básica: el robot social es un objeto (de elevadísima complejidad). El diseño industrial, una de las más importantes especialidades del diseño, es la disciplina mediante la cual se conciben, proyectan y desarrollan objetos o sistemas objetuales para la industria; pero, obviamente, el robot social es un sistema objetual con tales dimensiones cualitativas, que le impide ser clasificado exclusivamente en esta actividad proyectual. Debido a su extrema complejidad, el diseño y desarrollo de un androide involucra, de mejor manera y con mayor pertinencia, los saberes de las ingenierías (como la computacional, la electrónica y la mecánica). Así como ocurre con el desarrollo de automóviles y electrodomésticos, el diseño industrial aporta una perspectiva colaborativa a otras disciplinas que asumen rigurosamente el diseño y desarrollo funcional del sistema objetual. 
Entonces, si el robot social es un objeto (sistema objetual altamente sofisticado) que se destina a ser utilizado por un ser humano, podemos denominar a la persona que usa el objeto como usuario. Cuando digo que el "objeto se destina a ser utilizado" aludo directamente a la noción de función, es decir, lo que el diseñador espera que haga el objeto y, de manera consecuente, lo que se espera que el usuario haga con él: su expectativa de uso práctico en un contexto determinado (Cross, 1999). La conexión que se establece entre usuario y objeto implica así unos modos de vinculación evidentes y esenciales: la forma (del objeto) + la función (del objeto) en relación con la percepción (que tiene el usuario del objeto) + el uso (que le da el usuario al objeto). Forma y función están intrincadas de manera simbiótica e indisoluble, pues la forma tiene unas expectativas de percepción (estética y simbólica, es decir, de naturaleza funcional), y la función (práctica, predominantemente) está, asimismo, condicionada por la forma, para que pueda efectuarse su uso práctico. Sin embargo, la forma y la función, como las dos caras de una hoja de papel $^{3}$, deben ser discernidas conceptualmente por separado, para poder comprender la base estructural del diseño: cómo es el objeto (su apariencia) y qué hace (su acción o desempeño).

A continuación, mostraré cómo se realiza el proceso de diseño (forma y función) de robots sociales (objetos) destinados a asistir a pacientes con enfermedad de Alzheimer (usuarios) en ambientes domésticos determinados (contextos).

\section{Caracterización de aspectos formales y funcionales en el diseño de robots sociales humanoides}

La robótica social es un campo de estudio altamente especializado que involucra varias disciplinas para abordar el diseño y el desarrollo tecnológico de un robot, el cual, como es evidente, tiene dos grandes componentes: un sistema computacional, soportado en inteligencia artificial, y un sistema operacional mecánico. Gracias al sistema de inteligencia artificial (con vastas arquitecturas de programación), el robot procesa toda la información lingüística y visual del usuario, para interactuar con

él por medio de controladores de voz y movimiento.Y, por cuenta de un sistema mecánico, el androide se desplaza y realiza un conjunto de acciones basadas en las posibilidades funcionales que le brinda su arquitectura corporal, semejante a la humana. El robot tiene por lo tanto un cuerpo y una especie de "mente", que de manera coordinada, le permiten desempeñarse en correspondencia a una programación que se actualiza en las situaciones concretas de actuación con al usuario (Cuadros, 2010). 
Los robots "sirven" para apoyar actividades humanas propias del campo de la producción industrializada y de los escenarios sociales. Como lo revela el origen checo del término que utilizaría por primera vez Karel Capek, en su obra teatral Robots Universales Rossum (1920), son "servidores". Robota en checo significa trabajo, pero según su etimología del antiguo eslavo $r$ 'b, es más apropiado traducirlo como esclavo (Cuadros, 2010). Estos "esclavos artificiales" se desarrollaron bajo el cumplimiento del concepto de "mente extensa", desarrollado por Paul Humphreys (Vallverdú, 2007), una tendencia ambiciosa dentro de la computación y la informática que ha avanzado como resultado de la poderosa integración entre el ser humano y los medios tecnológicos. La extensión de los sistemas autómatas se ha producido en dos niveles: como máquinas y como replicantes (Sennet, 2012). El robot como máquina fundó el terreno conceptual del apoyo tecnológico en la era de la industrialización; robots que han servido para realizar desempeños de alta precisión y fuerza, superando ampliamente las posibilidades del ser humano. Los robots sociales son, en cambio, replicantes, intentos esforzados por replicar las características de lo humano en mecanismos artificiales. Como replicante, el robot social se articula a un espacio social híbrido (mente + instrumentos), distribuido y compartido por diversos agentes que trabajan de manera conjunta, según la noción de cognición distribuida de Hutchins y Norman (Vallverdú, 2007).

El propósito de la robótica social es que estos androides resulten muy semejantes a nosotros (formal y funcionalmente ${ }^{4}$ y no nos superen en fuerza necesariamente, pues se han concebido como recursos complementarios en nuestras acciones cotidianas. Este tipo de tendencia ha inspirado la gran mayoría de herramientas biomiméticas a lo largo de la historia, y no solamente en el sentido estricto de la emulación al cuerpo humano, sino como extensión de los medios de acción en general (McLuhan, 1996). La robótica social constituye, por lo tanto, una especialidad multidisciplinar que ha desbordado la noción de extensión del ser humano, tanto en el aspecto instrumental mecánico, como en el informacional: cuerpo y mente extendidos.

Similar a la noción de extensión, es la de aumentación. Los medios, como instrumentos de nuestra cultura material, siempre han avanzado en función de la ampliación de nuestra condición humana, a través de incorporaciones técnicas y tecnológicas que han permitido superar nuestras limitaciones biológicas: el vestido como aumentación de la piel, las herramientas como aumentación de nuestras manos, los vehículos como aumentación de nuestras piernas o el lenguaje como aumentación de nuestra mente (Mestres y Vives-Rigo, 2011). Por lo tanto, así como el ser humano siempre ha buscado aumentar su mente y su cuerpo mediante la técnica y la tecnología, lo hace además, con base en el recurso de la auto-emulación (podría denominarse antropo-mímesis). Así pues, el ser humano diseña herramientas cada vez más complejas de extensión de sus propios medios de interacción con el mundo, y lo hace poniéndose como centro de la emulación; el hombre crea al robot social “a su imagen y semejanza” y actúa frente a él como un espejo con el que se puede llegar a identificar y relacionarse, reconociéndolo como alteridad, probablemente en una intensificación de una cierta ilusión antropomórfica que se acentúa por el incremento de las condiciones de emulación que brinda el lenguaje verbal (Cuadros, 2005). 
Como hasta ahora lo he expuesto, el principio de diseño de robots sociales sería la antropo-mímesis, que implica un proceso de emulación del funcionamiento del ser humano, respecto a las dos categorías biológicas que lo sustentan: mente y cuerpo. Las condiciones imitativas del ser humano se basan, entonces, en las habilidades de desempeño del robot proporcionadas por un "cerebro" y un sistema comunicativo, para recibir información y actuar en correspondencia bajo arquitecturas de programación; es decir, todo lo relacionado con el extenso dominio de la inteligencia artificial. De otro lado, las acciones del autómata se ejecutan por medio de un sistema mecatrónico y se manifiestan en su conformación antropomórfica (cabeza y cuerpo). Así pues, me referiré en primer lugar, a la exploración de las funciones que se establecen en el diseño y desarrollo de la inteligencia artificial de un androide y, a continuación, realizaré la exploración de los criterios de forma y función que deben asumirse para el diseño de su cuerpo mecánico.

\section{La inteligencia artificial: "cerebro" funcional de un robot social}

La utilización del término inteligencia artificial debe entenderse en este acercamiento inicial a las nociones básicas de la robótica social, como la denominación que fuera aceptada y legitimada en tecnología informática, a partir de 1956, por John McCarthy, en una Conferencia en la Universidad de Darmouth, Estados Unidos. Alan Turing, padre de la computación y primer gran precursor de los avances de la inteligencia artificial, diseñó una prueba en la que vaticinó la capacidad de una máquina para suplantar a una persona, haciéndole creer a un interlocutor que tendría inteligencia humana. Él mismo tenía claro que las máquinas podrían fingir ser inteligentes, no que efectivamente llegarían a serlo (Mestres y Vives-Rego, 2012). No es probable que un robot logre desarrollar inteligencia, pero sí puede, en cambio, simularla, así como el pensamiento, el lenguaje, la consciencia o el conocimiento. A pesar de la claridad que tuvo Turing en la proyección de su concepto, existe una creencia generalizada respecto a la posibilidad de que un sistema computacional pueda ser inteligente y es apenas comprensible, por la misma configuración sintáctica del término. El adjetivo "artificial” no implica exclusivamente que la inteligencia humana puede ser simulada, sino que también puede "darse" artificialmente. Lo "artificial" no excluye la autenticidad de la cualidad computacional que puede surgir (como resultado de la emulación a la inteligencia humana). Si tomamos la expresión: "Espera un momento que el computador está pensando", o si miramos algún prosaico augurio como: "las máquinas también podrán llegar a tener consciencia", vemos que el uso de la palabra "pensando" y "consciencia", aluden a facultades ónticas verdaderas, no a analogías del sentido común. Y más curioso aún en esa frase es el empleo de la conjunción “también”, porque implica la posibilidad de que una máquina podría obtener la capacidad de pensar como la que tiene una persona, o sea que valida la autenticidad facultativa del artificio. Que la computadora Blue Deep le ganara una partida de Ajedrez a Gary Kasparov, no ocurrió porque esta máquina fuera más inteligente que el 
prestigioso ajedrecista, sino porque podía “calcular”, a una velocidad asombrosa, todas las posibles movidas de su contrincante y, de esta manera, responder con las jugadas más apropiadas para obtener la victoria. La máquina una vez más superó al hombre, pero no en inteligencia. Por lo tanto, el uso del término "inteligencia artificial" no está legitimando de ninguna manera el hecho de que los robots sean "realmente" inteligentes, ni que puedan pensar, sentir, obtener consciencia o desarrollar lenguaje. Lo relevante del asunto es que la inteligencia artificial abre la puerta a la reflexión profunda sobre los mecanismos tecnológicos y simbólicos de simulación que llevan a producir efectos tan intensos de creencia; cómo el usuario se permite creer que la experiencia con un androide es real y verdadera.

En el campo de la inteligencia artificial se han desarrollado proyectos relacionados con el desarrollo de robots sociales capaces de llevar a cabo funciones ${ }^{5}$ como las que realizamos los seres humanos e incluso superiores, que se pueden clasificar en dos grandes categorías: funciones de análisis (cómo el robot recibe y procesa información) y funciones de síntesis (cómo actúa el robot). Para las primeras, la inteligencia artificial ha intentado comprender la manera como ocurren los fenómenos mentales del ser humano desde una perspectiva lógica; es decir, que la concepción y replicación de modelos de análisis como los que realiza el cerebro humano puedan ser imitados matemáticamente en funciones y variables de programación (enfoque funcionalista). En cuanto a las funciones de síntesis, se han explorado de manera rigurosa los mecanismos que reproducen patrones de comportamiento humano mediante la combinación de arquitecturas de programación en la interacción con usuarios en contextos de intervención en tiempo real (Cañas y Matellán, 2006). Esto permite que las actuaciones esperadas de un robot (su "comportamiento") se produzcan como resultado de las reacciones que éste tiene ante la interacción humana, sobre una sólida base de programación (ramificación de posibles respuestas). La investigación en inteligencia artificial para los procesos de análisis y síntesis del robot han producido extraordinarios avances en el desarrollo de "capacidades cognitivas robóticas" y "conocimiento contextual", facultades de simulación (por supuesto) que posibilitan que, ante los desafíos de interacción con el usuario en contextos demasiado complejos, el androide pueda reconfigurarse y modificar su "comportamiento" de forma autónoma mediante mecanismos de "interpretación", "aprendizaje” y acceso a software remoto por internet (Becerra, Bellas y Duro, 2006).

\section{Funciones de análisis y síntesis en los robots sociales}

El sistema de inteligencia artificial de un robot realiza procesos que simulan atención, razonamiento, reconocimiento o actitud, entre otros. Estas facultades le permiten al cerebro artificial de la máquina,jerarquizar los sujetos, objetos y acciones, valorar la información lingüística y visual que recibe, identificar similitudes y diferencias de lo que capta, y configurar un marco de posibles acciones a seguir. De hecho, las investigaciones más recientes empiezan a involucrar la incorporación de emociones sintéticas (Vallverdú, 2007), reproducidas desde una perspectiva funcionalista, para optimizar la pertinencia de las respuestas (Damasio, 2007) ${ }^{6}$, mejorar sus competencias 
e incrementar su autonomía. Los expertos en el área le llaman a este conjunto de acciones simuladas, aprendizaje, ${ }^{7}$ recurso mediante el cual el robot no sólo opera bajo una programación previa sino que incorpora información nueva y la utiliza para reconfigurarse permanentemente. Una de las expectativas de desarrollo en esta vía, es la de la consciencia artificial, vertiente que hace énfasis en la capacidad de la máquina de emular al ser humano en los procesos de percepción y propiocepción; "la información sensorial que posee sobre su estado"» (Becerra, Bellas y Duro, 2006, p.345). Esta facultad de concebir "actos intencionales" en lo que "percibe" externa e internamente, y tener "consciencia de sí mismo" han sido consideradas por los especialistas como un paso de absoluta importancia para el desarrollo de emociones artificiales. Algunas funciones de la consciencia artificial que han sido categorizadas son las siguientes: atención, balance de la situación, búsqueda global, proceso de reconocimiento implícito y explícito, contextualización, predicción sensorial, memorización modal y auto-coordinación (Arrabales y Sanchios de Miguel, 2006).

Mediante la atención, que puede ser de dos clases, fenoménica (intransitiva) y de acceso (proposicional), el androide puede discriminar las acciones de percepción externa e interna, semejantes a las experiencias del ser humano, y, además, disponerse para el "razonamiento", como la acción de "recordar" y seleccionar un repertorio verbal, por ejemplo. Una metáfora muy acertada para comprender este fenómeno es la del "teatro de la consciencia" de Bernard Baars, la cual representa la consciencia como un foco de luz sobre el escenario de una obra teatral, direccionado por la atención. Así pues, hemos constituido una memoria de contenidos conscientes (o memoria de trabajo) que se articula con mecanismos inconscientes (el resto de actores y elementos no iluminados por la luz). De modo que lo que hacemos consciente es lo que ve la "audiencia" gracias a la focalización. Mientras tanto, el liderazgo de la información inconsciente la asume el "dramaturgo", quien, tras bambalinas, ha construido una trama de contextos y creencias que subyacen a las acciones protagónicas. La metáfora del "teatro de la consciencia" aporta así, un esquema de desarrollo para la dotación de consciencia artificial en robots sociales. Desde el enfoque funcionalista de procesos cognitivos de consciencia se investiga cómo se gestiona el acceso y el control de los actos inconscientes y cómo se articulan mediante un proceso secuencial consciente. Los procesos "inconscientes" (implícitos) del robot le permiten tener una vasta colección de "actitudes" automáticas, mientras que los procesos “conscientes” (explícitos) guían su “comportamiento”. La aplicación de un modelo artificial de consciencia y la implantación de emociones sintéticas, contribuirán a que el autómata pueda manejar de manera más adecuada situaciones no esperadas o problemáticas, con base en la imitación de procesos racionales, sociales y éticos (Arrabales et al., 2006)

Otro concepto que se deriva de estas indagaciones es el de conocimiento artificial, que surge directamente de las circunstancias de recepción y procesamiento de información en situación. El conocimiento contextual que realiza la máquina se produce gracias a unos mecanismos de captura, apoyado en un sistema de sensores y un completo equipo de comunicación externa e interna (Núñez et al., 2011). Con el fin de hacer un modelado del contexto, el sistema de inteligencia artificial se programa con ontologías semánticas, 
que le permiten acceder a un extenso repertorio de significados para "interpretar" las imágenes y palabras que se le suministran. Finalmente, por medio de unos motores de reglas que le permiten implementar "técnicas de aprendizaje" y agregación de información, el robot realiza inferencias sobre las acciones e intenciones del usuario. Estos minuciosos procesamientos computacionales y electrónicos que he descrito del organismo artificial, constituyen un sofisticado mecanismo de "representación del conocimiento"; esto es, los modos como la inteligencia artificial de un robot le permite acceder y procesar la información que "percibe". Por ejemplo, la evaluación que puede hacer un robot asistencial del estado emocional de un paciente que se rehusara a hablar, estaría basado en la medición de sus signos vitales y en una comparación visual de sus expresiones corporales y gestuales no verbales (Mendizábal, León, Ruiz y Alutiz, 2013). Esta situación hipotética sería una de las tres posibilidades en las que, según la acreditada investigadora del MIT (Massachussets Institute of Technology), Cynthia Breazeal $^{10}$, el robot social puede relacionarse emocionalmente: Permeabilidad emocional ante usuarios, Simulación de emociones del robot y Diseño amable (Vallverdú, 2007).

Las emociones sintéticas se integrarían, entonces, como mecanismos de atención urgente (disposicionales, graduales y articulables) listos para interrumpir el procesamiento de la información programada que se esté llevando a cabo y reconfigurar sus disposiciones a la acción; una simulación de actos de decisión (Modelo de Sloman, 1987). La manifestación definitiva del androide depende, así, de una articulación entre contexto, "percepción” y “experiencia” (Modelo de Frijda, 1986). Si las nociones psicológicas que sustentan estas hipótesis se aplican funcionalmente a la inteligencia artificial, se espera que a mayor grado de emociones sintéticas el robot sea más eficaz en la "toma de decisiones" (Bedia, Corchado y Ostalé, 2006).

Las fases de análisis y síntesis que realiza el sistema de inteligencia artificial de un robot social son simultáneas y extremadamente veloces. Incluso en la explicación misma del fenómeno, es inevitable referirse a cuestiones exclusivamente analíticas o sintéticas, porque son procesos muy intrincados. Pero en un nivel general, se puede comprender que lo esencial en la fase de análisis gira en torno a las entradas de la información y a los mecanismos que requiere el sistema para orientar su flujo. En la fase de síntesis, en cambio, ocurren las acciones que realiza la máquina como respuesta a las entradas de información y, también, como resultado de los procesamientos que introduce la articulación entre los esquemas de programación y los de captación de contextos.

Por lo que he descrito hasta el momento, se puede concluir que los procesos de análisis y síntesis realizados por un robot gracias a su inteligencia artificial, se circunscriben en un enorme modelo cognitivo-afectivo que está fundamentado en los siguientes componentes: consciencia, conocimiento y aprendizaje artificiales. Podríamos pensar en más atributos como la atención, la emoción o la percepción, pero todos estarían contenidos en estas tres grandes categorías; la atención, por ejemplo, es un elemento clave de la consciencia, la percepción aparece arropada por el conocimiento y la emoción por el aprendizaje. Así pues, se puede establecer que, en una fase pragmática, las principales habilidades de acción de un robot social correspondientes y consecuentes a los tres componentes mencionados son: expresión, enunciación y ejecución artificiales. 


\section{Las acciones "inteligentes" del robot social: funciones básicas para la interacción comunicativa}

Si el modelo cognitivo-afectivo de un androide se basa en tres grandes componentes como la consciencia, el conocimiento y el aprendizaje artificiales, los tres grandes conjuntos de acciones correspondientes son: la expresión, la enunciación y la ejecución artificiales.

La expresión artificial se produce como un "acto de consciencia" que se determina ante un estímulo que, de igual manera, se hace "consciente”; es una respuesta que el robot manifiesta luego de "interpretar" la información proporcionada por el usuario y que se deriva de procesos de programación combinados con estímulos del contexto.

La enunciación artificial es una acción consecuente del conocimiento artificial, porque sólo en la medida en que el androide evalúa sus "experiencias" y las articula con sus extensos archivos de programación (de la misma manera como lo hace el cerebro humano), puede expresarse lingüísticamente, produciendo frases que estarán destinadas a satisfacer algún requerimiento del usuario o indicar la necesidad de mayor información para actuar de manera pertinente. Ante cualquier solicitud del usuario, la máquina responderá afirmativa o negativamente, hará una pregunta o pasará directamente a realizar una tarea específica.

Y en cuanto a la ejecución artificial, es plausible concluir que es la acción más compleja que puede realizar el robot en cada proceso de interacción, antes de iniciarse otro. Por eso, procede del aprendizaje artificial, porque sólo es posible que sea ejecutada luego de haber llevado a cabo una "toma de decisión”.

Estas funciones básicas para la interacción son acciones que se califican como inteligentes, porque evidencian la capacidad de la máquina de operar con autonomía y eficacia interactiva. Una de las habilidades más importantes que se establecen en el diseño de robots sociales, es el conjunto de acciones requeridas para la comunicación, pues van más allá de constituir un medio de transmisión de información en tanto procuran la mutua retroalimentación de flujos de contenido lingüístico. Aunque las más avanzadas versiones comienzan a sobresalir por ejecutar, además, tareas de manipulación fina como coger vasos, sostener bandejas y desplazarse para atender personas, las acciones comunicativas son indispensables para apoyar procesos de acompañamiento a usuarios con discapacidad cognitiva. El robot social asistencial aún está lejos de ejecutar tareas tan perfeccionadas como limpiar, cocinar, reparar objetos o lavar la ropa, pero como es un compañero permanente, sus funciones son supremamente necesarias como interlocutor para la comunicación, incentivando al paciente a ejercitar su mente mediante el diálogo. Por otra parte, cumple una labor fundamental (destinada a desencadenar acciones concretas), su desempeño secretarial: estar pendiente de recordarle acciones y actividades programadas. Finalmente, son acciones de mayor trascendencia dentro del campo de la inteligencia social, para el cual el androide ha sido diseñado, pues la articulación de los procesos de recepción y de acción que realiza el robot proporcionan la grandiosa proeza de la interacción; el intercambio comunicativo entre sujeto y objeto (simulador de sujeto) en formas de comunicación verbal y no verbal. 
Pues bien, si se considera válido el argumento de que el desempeño más importante que debe realizar un robot social es el conjunto de acciones relacionadas con la comunicación (precisamente por ser androides de la categoría social), es necesario comprender cuáles son los elementos que constituyen su intrincada configuración.

La noción de comunicación que estoy empleando en este trabajo, se refiere a un proceso de intercambio de información, no simplemente a los flujos unidireccionales de datos. Esta postura está más cercana a la etimología del término communicare, "puesta en común”, cuyo propósito es la acción común; es decir, que no alude a los sofisticados mecanismos de los medios de transmisión masivos de largo alcance ${ }^{11}$ (Baylon y Mignot, 1996). La comunicación es una habilidad que, evidentemente, también tienen los animales (algunos con mayor nivel de complejidad que otros), y no depende exclusivamente de la capacidad de lenguaje, pues no está determinada por la actuación consciente. Entonces, la condición básica para que se pueda considerar un fenómeno de comunicación como tal, es que la información que se produce entre dos sujetos sea intercambiada recíprocamente, es decir, mutuamente retroalimentada. El contenido de la información transmitida no siempre será lingüístico, pues hemos sido testigos de innumerables interacciones comunicativas entre personas mediante señas y gestos (comunicación no verbal).

La comunicación cuando es directa, como una conversación presencial, permite ser discernida como un ciclo procesual de intercambio de información que se produce entre dos personas, en dos fases. En el inicio de una conversación, un EMISOR A dirige un contenido de información, en un MENSAJE 1, a un RECEPTOR B. A continuación, B (que ya no es receptor) se instituye en EMISOR B dirige un contenido de información en un MENSAJE 2 (relacionado con el MENSAJE 1) al RECEPTOR A, como respuesta o en consecuencia. Hasta ahí se configura el primer ciclo de interacción en una conversación, que continuará actualizándose en innumerables períodos. Estos ciclos de interacción comunicativa pueden representarse de manera lineal, pero en muchos momentos son simultáneos, pues mientras un emisor se expresa, también está recibiendo información visual del receptor. Presentaré un ejemplo: Supongamos que en el campus universitario donde trabajo, un transeúnte me aborda, dirigiéndome el siguiente mensaje lingüístico: "Buenos días, hágame un favor: ¿usted me puede indicar dónde queda el edificio de administración central?”. Esta consulta sería la fase 1 de un ciclo de interacción comunicativa. Ante lo cual yo procederé con la fase 2, diciendo algo como: "Discúlpeme, ¿puede repetir la pregunta?... no lo escuché porque iba distraído”. Ahora, yo como emisor, expreso un contenido lingüístico que no es la respuesta a la pregunta del desconocido, pero es consecuente y coherente como intercambio de información. Cuando la persona extraviada me repite la pregunta, iniciamos el segundo ciclo dentro de la conversación y así continuaremos sucesivamente hasta que finalice la situación comunicativa entre él y yo. Mientras se producen los viajes de contenido informativo lingüístico entre ambos, se establecen también momentos de solapamiento de información no verbal. Cuando le explicaba la ubicación del edificio de administración con un mensaje de dos naturalezas, lingüístico y gestual, observaba su rostro para inferir si estaba comprendiendo las indicaciones. 
El visitante que no conoce la universidad y yo, somos dos sujetos que intercambiaron información verbal y no verbal, con el propósito de que el primero obtuviera información útil para su desplazamiento eficaz; el propósito de la comunicación siempre tiene un fin práctico y por lo general, procura acciones que afectan a una comunidad, como orientar a un desorientado o motivar cambios de conducta, entre tantas probables acciones de implicación colectiva. Cuando la conversación sucede entre más personas, se generan los mismos ciclos entre polos, pero de manera simultánea: mientras A escucha a B, también observa a C. Mientras C observa a A, escucha también a B. En algún instante $\mathrm{C}$ observa a $\mathrm{B}$ y rastrea la articulación de los gestos con sus palabras.

La relación que he mostrado para explicar las situaciones de comunicación puede suceder entre seres humanos, entre humanos y animales, entre animales y, por supuesto, entre humanos y robots. Esto de entrada plantea una condición inquietante: o la comunicación no es exclusivamente intersubjetiva o la intersubjetividad no es un fenómeno que se produce exclusivamente entre personas, pero, de momento, puedo adelantarme a concluir que la situación comunicacional que se presenta entre una persona y un robot no es artificial ni es simulada, es real porque se basa en un intercambio de información que genera acciones consecuentes. Entonces, una vez descrita la complejidad de una situación comunicativa natural entre seres humanos, es posible establecer una relación (de tipo funcionalista) con los fenómenos comunicativos entre pacientes y robots sociales. A continuación explicaré, entonces, cuáles son los componentes funcionales básicos requeridos por una máquina "inteligente" para ejercer intercambios eficaces y coherentes de información con el usuario.

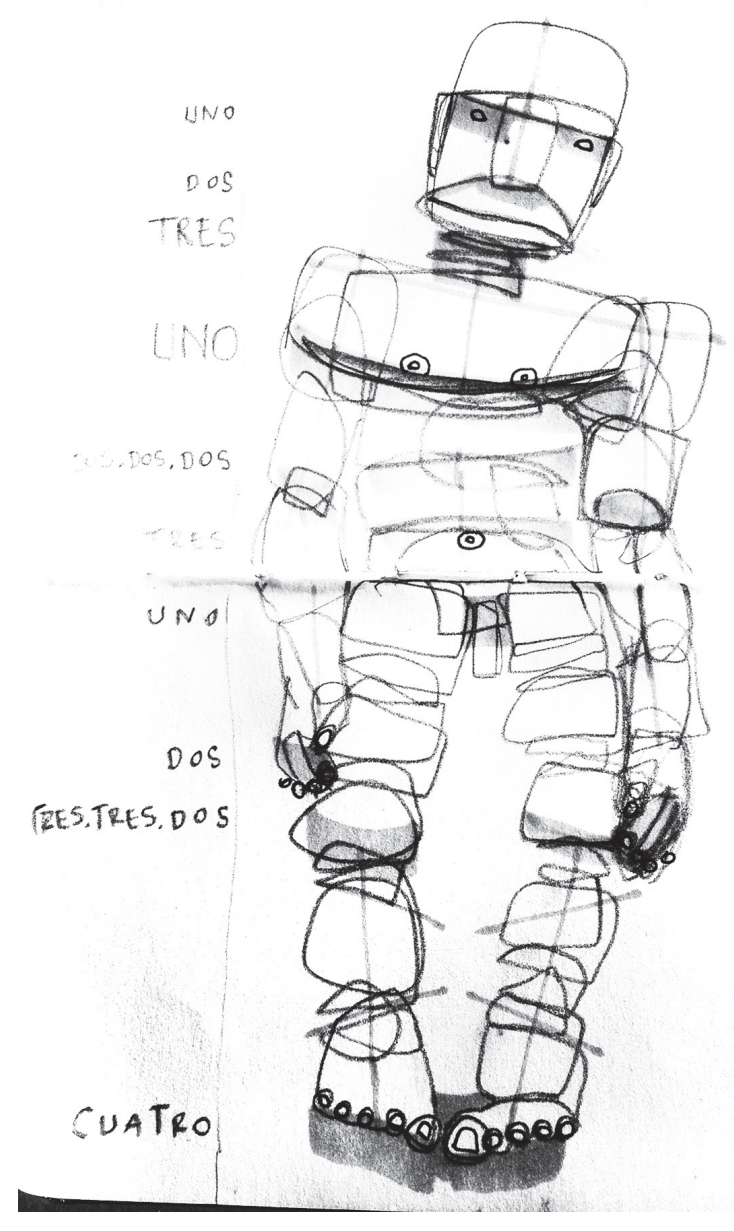

\section{El lenguaje como medio posibilitador de la aparente intersubjetividad entre el robot y el usuario}

Como ya lo había mencionado, los tres grandes conjuntos de acciones que un robot social asistencial es capaz de realizar son: expresión, enunciación y ejecución artificiales. Todo el gigantesco proceso que ello implica gira en torno, principalmente, al desempeño de sus habilidades comunicativas. Para ello debe contar con un sistema de recepción y procesamiento de información verbo-icónica, administrado por un cerebro artificial que jerarquice y valore los datos, identifique personas, objetos y acciones, y establezca las acciones a seguir; desde la expresión más elemental como guardar silencio hasta desplazarse y ejecutar tareas prácticas. Para actuar en correspondencia, debe contar además con un cuerpo mecánico que le permita moverse y ejecutar ciertas acciones de motricidad fina, $y$ una cabeza mecánica, desde donde emitiría mensajes sonoros verbales y en la cual estaría instalado sus sistema de recepción audio-visual. 
Para cumplir a cabalidad con este arduo desafío de interacción, el sistema artificial debe estar dotado de los siguientes mecanismos para su funcionamiento:

Cabeza: - Sistema cerebral de inteligencia artificial multiagente bio-inspirado (controladores, recepción, procesamiento y reconocimiento de datos y aprendizaje).

- Sensores audio-visuales y táctiles (de movimiento y temperatura).

- Sistema de emisión de voz.

Cuerpo: - Sistema de actuadores mecánicos (para desplazamiento y movilidad corporal).

Uno de los componentes de mayor importancia en cualquier interacción comunicativa es la lectura que hace el sistema artificial de códigos verbo-icónicos y a partir de allí, su correspondiente enunciación en la misma dimensión. Los signos verbo-icónicos son una manifestación esencial del lenguaje natural (humano) mediante palabras expresadas vocalmente o por escrito, junto a los elementos no lingüísticos, tanto sonoros como visuales (paralingüísticos, tales como el carraspeo, el tono de la voz ${ }^{12}$, el volumen, etc. y extralingüísticos como las imágenes visuales) $)^{13}$. Así pues, en una primera instancia el robot social debe tener una programación lingüística, soportado en extensas arquitecturas de información que le permitan encontrar el sentido de las palabras que recibe, y un eficaz sistema de reconocimiento audio-visual. De igual modo, en una segunda instancia, debe ser capaz de construir frases con sentido (para el usuario) y enunciarlas por medio de un sistema de emisión sonora, involucrando una simulación afectiva con base en tales aspectos paralinguísticos y extralingüísticos (Baylon y Mignot, 1996)

Este extraordinario intercambio de información que el autómata es capaz de realizar con el paciente, no es más que una simulación muy perfeccionada de intersubjetividad, pues dicho intercambio no se basa realmente en un dialéctica de experiencias. El lenguaje como facultad del usuario y como recurso de mediación del equipo de diseñadores, se instituye como medio posibilitador de la aparente intersubjetividad entre el robot y el paciente. El sujeto experimenta actos conscientes con la máquina y hace un uso efectivo del lenguaje natural, mientras que el androide solamente realiza una interacción mediática, automática y electrónica, proporcionada por los mecanismos de representación informática y computacional de los desarrolladores en robótica. Así que, en sentido estricto, lo que se produce es una interacción entre un sujeto y un objeto que simula ser sujeto. Es importante recordar que el sujeto es quien le asigna al objeto los atributos de sentido estético y simbólico, porque no están dados en la compleja representación artificial. Al respecto, Searle (2006) presenta una precisión indispensable entre lo que él denomina intencionalidad original e intencionalidad derivada, y propone un ejemplo didáctico: un mapa contiene información sobre el modo de llegar a un lugar llamado San José, expresada en símbolos que representan ciudades, autopistas y otros elementos. El lector del mapa, que está en camino a dicha localidad, tiene un conjunto de creencias, recuerdos y conocimientos sobre cómo llegar allí. Los estados mentales del lector, en el segundo caso, son una manifestación de intencionalidad 
original o intrínseca. El mapa, también contiene intencionalidad, pero derivada de la que dibujó allí; el cartógrafo que lo produjo: "El mapa es sólo una lámina de fibra de celulosa con manchas de tinta. Cualquiera sea su intencionalidad, le es impuesta por la intencionalidad original de los seres humanos" (Searle, 2006, p.19).

El robot simula ser inteligente, consciente y pensante; cualidades para las cuales es necesario disponer de habilidades lingüísticas. La facultad del lenguaje que hemos desarrollado los seres humanos es algo tan complejo que es muy difícil establecer sus límites. Pero, gracias al ejercicio que propuso John Searle con la metáfora de la habitación china ${ }^{14}$, se puede comprender por qué no existe lenguaje en una máquina "inteligente" (2006). La situación que él plantea es la de estar encerrado en una habitación donde solamente se dispone de cajas llenas de símbolos chinos y un completo manual de instrucciones, no un diccionario. Así, el instructivo, que es la metáfora de un programa informático computacional, me brinda la posibilidad de escoger los símbolos apropiados para responder preguntas que me hagan en mandarín, y responderlas acertadamente. Afuera, las respuestas que revise, por ejemplo, un chino, serán evaluadas satisfactoriamente, aunque yo ignore absolutamente lo que estoy reproduciendo. De igual manera, los signos lingüísticos que utiliza la programación de un ente artificial son seleccionados, relacionados y evaluados automáticamente por procesos de comparación formal. Como cuando un niño de 2 años intenta imitar el dibujo de una letra (por ejemplo, la A) y se evalúa el éxito o fracaso de su producción con base en los criterios de semejanza de la copia respecto al original, no en el significado de la letra, ni las relaciones de sentido sintácticas o semánticas (por qué es una vocal, cómo suena, cómo se emplea para formar sílabas y palabras o cómo afecta el género como sufijo). El cerebro computacional no lee en un sentido lingüístico, sólo recibe, compara y evalúa aspectos formales de pequeña o gran complejidad cuantitativa. Bajo la misma analogía, alguien puede aprender a escribir ruso pero no comprenderlo, o alguien ser capaz de cantar en francés, con excelente pronunciación, pero desconocer completamente el idioma.

Una vez revisados los aspectos funcionales más relevantes que debe cumplir un robot social, podemos concluir que, dentro del conjunto de acciones comunicativas más complejas que puede realizar, es indispensable la de poder iniciar y mantener una conversación con el paciente, preguntando y simulando que presta atención mediante expresiones no verbales (Salichs et al., 2014). Esto implica que el usuario se disponga a creer en la simulación, que se deje llevar por la situación de fingimiento debido a que el androide es tan sofisticado que reconoce las diversas posibilidades de reacción que se generen en su interlocutor. La habilidad de reconocimiento es sustancial; reconocimiento facial (identificación formal y gestual de los usuarios), de voz (identificación del hablante, comprensión de contenidos verbales y no verbales), de situaciones (placidez, irritación, peligro, actividades que no deba interrumpir, etc.) y de contenidos lingüísticos sintácticos y semánticos, por supuesto. La eficacia de estos niveles de reconocimiento que realiza la máquina están directamente relacionados con reacciones esperadas en el paciente, porque éste se siente escuchado y valorado. Por otra parte, en un aspecto mucho más específico en cuanto a lo asistencial práctico, el robot debe estar atento a identificar estados de desorientación del enfermo y actuar oportunamente, suministrándole la información pertinente. Igualmente, debe reconocer un probable estado de intranquilidad e intentar calmarlo con palabras, reproduciendo grabaciones de audio de la familia o contactándolos de manera remota. Las acciones "inteligentes" del androide fomentan, además, en un nivel simbólico, un balance de diálogos de autonomía: en la medida en que la máquina asiste eficazmente al paciente 
en tareas cotidianas, pero sin hacerlo sentir inútil, como un sofisticado secretario robótico, y del otro lado, el anciano siente que tiene el control de las situaciones a su alrededor, relacionándose afectivamente con la máquina sin la preocupación que le ocasionaría el cuidado de una mascota (Salichs et al., 2014).

El robot social es la gran simulación de la vida inteligente, capaz de sustituir personas y proyectar las posibilidades de intercambio informacional a dimensiones extraordinarias. "La forma sigue la función", declaró contundentemente el arquitecto Louis Sullivan, pero más recientemente, Alexander Manu (1998) ha actualizado la complejización de este principio: "la forma sigue la posibilidad": las experiencias que produce la interacción con la máquina "inteligente", es el punto de propulsión que lleva al usuario a obtener experiencias más intensas, estimulantes y trascendentes.

\section{La apariencia del robot social asistencial: La forma sigue la función y la posibilidad}

En robótica social, el cerebro de la máquina controla un cuerpo mecánico que, como ya he mencionado, también es el resultado de una emulación formal y funcional del ser humano. A continuación me referiré al proceso de diseño de un robot humanoide,por ser el de mayor éxito en las evaluaciones de comprobación que se han realizado hasta el momento. Los atributos antorpomórficos y el conjunto de funcionalidades operativas y de interacción lingüística basadas en la emulación humana incrementan la eficacia en la relación social artificial. Por una parte, porque ergonómicamente facilita operaciones prácticas de desplazamiento, agarre de objetos y otras funciones elementales y, por otra, porque simbólicamente es más agradable para las situaciones de interacción lingüística. Por lo tanto, cabeza y cuerpo del robot deben ser diseñados para satisfacer dos grandes necesidades del usuario de la $3^{\mathrm{a}}$ edad: apoyo práctico y apoyo simbólico-afectivo.

Un robot social humanoide es copartícipe del mundo de la vida del usuario y de sus objetos. Habita con él su residencia y utiliza un buen número de elementos que se encuentran a disposición, como el mobiliario, los elementos del hogar y algunos electrodomésticos: una herramienta que usa herramientas (Schutz, 2009). A diferencia de electrodomésticos como el televisor y la radio que, aparte de entretener por sus contenidos,

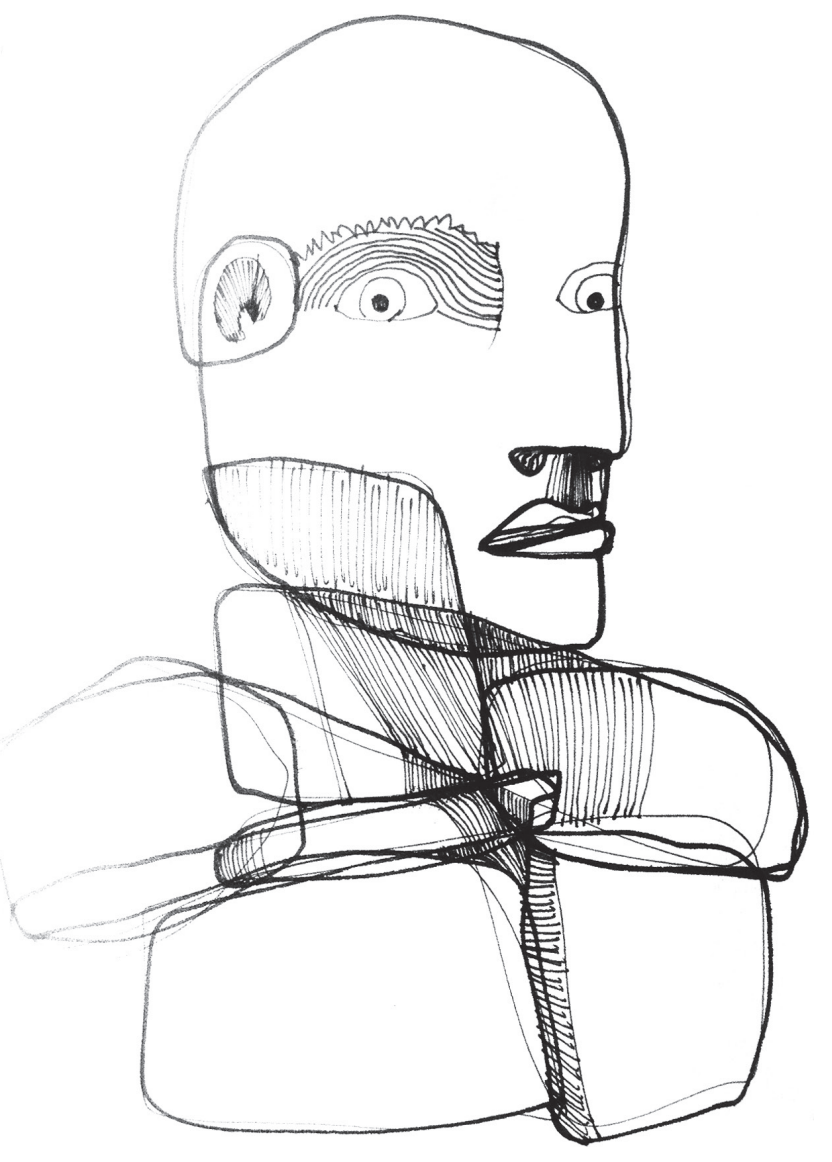
acompañan al individuo por la emisión de sonidos que producen, un robot es percibido como un acompañante eficaz porque tiene movimiento; movimiento autónomo e interactivo además, razón por la cual resulta fundamental como simulador de organismo viviente. $\mathrm{Si}$, adicionalmente, 
este movimiento autónomo que manifiesta el androide es fluido, resulta más parecido al movimiento humano y, por lo tanto, será mayor la sensación de familiaridad que produzca en el paciente. Así, es válido inferir que el diseño del robot social humanoide debe resolver los desafíos de apariencia formal y funcionalidad del movimiento, en primer término.

Con base en la pregunta fundamentalmente estética ¿cuál sería la apariencia preferida por las personas de un robot destinado a interactuar con ellas?, se han realizado muchos estudios que concluyen algo bastante curioso; no son mejor aceptadas las formas más semejantes a lo humano, ni en apariencia, ni en tamaño. Los robots que intentan emular el aspecto del color, la materialidad y demás elementos detallados del cuerpo y el rostro de un ser humano, fracasan y se tornan un poco espeluznantes. Tal vez, cuando se logren emular óptimamente las acciones del autómata, pueda pasarse a la simulación exacta de los aspectos formales, pero al no haber ese nivel en ambos aspectos, los acercamientos resultan contraproducentes. Este fenómeno lo explica bien la hipótesis del "Valle inquietante”, de Masahiro Mori (Garrell y Sanfeliu, 2010), quien planteó que existe una brecha entre el robot humanoide de aspectos antropomórficos que causa empatía y un robot extremadamente parecido a una persona (geminoide), que causa rechazo. Por esta razón, el diseño de robots debe guardar una mayor relación icónica con personajes humanoides caricaturizados, que con la apariencia humana como tal. El androide no debe dejar de verse como tal, porque en su propia identidad robótica, produce un vínculo afectivo semejante al del dueño y su mascota. El criterio de búsqueda de la semejanza no debe reposar en la apariencia óptima que plantea la falacia "lo más parecido posible al humano", sino en las bases de la familiaridad y la amigabilidad, que es algo muy diferente. Aunque el robot emula lo humano y es configurado por imitación en cuanto tal, se espera que la máquina sea explícitamente un robot. Es por esto que la forma y la función de movimiento que deben expresar los robots sociales humanoides deben proyectar una "personalidad distintiva", estar dotados de un carácter artificial que haga un especial acento en la sensación de particularidad y esté dotado de un carisma al estilo de un personaje dibujado (un cartoon). Esta marca (Schutz, 2009) es un elemento esencial en la manifestación simbólica de la herramienta y, curiosamente, entra en diálogo con algunos principios básicos del diseño de identidad visual corporativa y el diseño de personajes ${ }^{15}$.

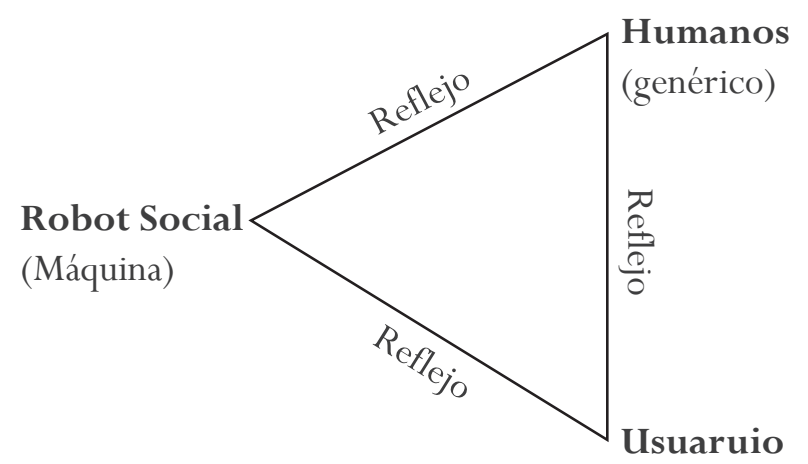

(Humano Particular) 
Pues bien, según las acciones que realiza el autómata y las relaciones que condicionan sus formas y movimientos, se pueden establecer unos criterios generales para el diseño de robots sociales (tanto de la cabeza como del cuerpo): dimensión, proporción, semejanza y gestualidad. La preferencia en cuanto a dimensión es que sean inferiores a 1.50 $\mathrm{cm}$, es decir, que al ser de menor tamaño que un adulto, alude a las características amigables de una especie de mascota tipo cartoon. Así mismo, la proporción debe guardar esta relación de incremento del tamaño de la cabeza en relación con el cuerpo o los ojos (cuando son visibles) en relación con el rostro. En cuanto a la semejanza, existe una variada gama de casos, desde los que rebasan la función matemática del "valle inquietante" y emulan la más alta iconicidad al ser humano (de acuerdo con distintas etnias) hasta los que guardan una distancia prudente, como los que se inspiran en el aspecto amigable de los personajes de tiras cómicas. Y, finalmente, la gestualidad es uno de los más importantes atributos que compromete el cuerpo y el rostro del robot, tanto en sus aspectos formales como de movimiento. Algunos casos en los que se ha explorado la fisonomía facial típica de ojos con párpados, nariz y boca (que, bajo la noción del "valle inquietante", no garantiza una mayor aceptabilidad), la gestualidad es muy importante para que el robot apoye de manera coherente sus manifestaciones verbales. Pero muchos robots, incluso los más desarrollados hasta el momento, carecen de detalles faciales; tienen, como máximo, un par de áreas oculares. Así pues, es primordial que se expresen gestualmente mediante el cuerpo: movimiento y velocidad de la cabeza y las extremidades.

En conclusión, los robots humanoides son más efectivos en sus desempeños de interacción social, cuando forma y función se articulan, de tal modo que seducen al usuario como lo hace un personaje de tiras cómicas o dibujos animados. Los esfuerzos de los diseñadores no deben encaminarse a que el androide se parezca demasiado a una persona, porque en su estatus de ente artificial es preferible que emule, principalmente, las características de amigabilidad de personajes de ensoñación. Al ser explícitamente fantásticos, los robots son más cautivadores en sus mecanismos de generación de experiencias fascinantes, como maravillosos y sofisticados juguetes. Si la forma va más allá de la función y sigue la posibilidad, el proceso de diseño de robots sociales es potencializador de experiencias lúdicas por parte del paciente; porque más importante que el respaldo en un nivel práctico para el bienestar físico del anciano, es el apoyo sicológico que se le pueda brindar (Núñez et al, 2011). Por todo lo anterior, es plausible concluir que el diseño de robots sociales humanoides con propósitos asistenciales es un campo de aplicación vital del diseño de experiencias y por lo tanto una modalidad discursiva de la robótica social. 


\section{b. DISEÑO DE EXPERIENCIAS COMO MODALIDAD DISCURSIVA EN LA ROBÓTICA SOCIAL}

De lo visto hasta ahora, considero que es pertinente sintetizar la siguiente estructura respecto a las relaciones que pueden ser establecidas entre un usuario (sujeto) y un robot (objeto), gracias al lenguaje:

El proceso de diseño durante el cual se establece un conglomerado de atributos de forma, función y posibilidad del robot, es el primer gran componente. El recurso central que soporta todo este desarrollo desde la idea hasta la concreción es el principio de emulación, aumentación o imitación de la funcionalidad y apariencia humanas. La intencionalidad original de un equipo de diseñadores y desarrolladores (sujetos) es, fundamentalmente, la de representar un rol social; asumir el desempeño de una persona que atiende a un paciente en aspectos prácticos y que lo apoya en niveles afectivos.

Lo diseñado, el resultado del proceso, el robot social humanoide que se manifiesta como intencionalidad derivada, es el segundo componente. El recurso principal que sustenta este objeto-medio resultante es el principio de simulación, "hacerse pasar por", fingir ser lo que no es; es decir, lo emulado.

La experiencia de uso que se produce en una cierta situación interactiva de la realidad del mundo de la vida del paciente, es el tercer componente. El recurso fundamental que posibilita la vivencia es el principio de significación, la capacidad que tiene el sujeto de asociar varios niveles de significados a lo que percibe. La intencionalidad intrínseca del usuario le permite actuar sobre el robot con toda la fuerza de su bagaje mental en un contexto de complejas particularidades; las intenciones que impone el usuario marcan el rumbo a la posibilidad, no sólo respecto a la funcionalidad del artificio.

$\begin{array}{lll}\text { Diseño } \rightarrow & \text { Resultado } \rightarrow & \text { Experiencia } \\ \text { Diseñador } & \text { Robot } & \text { Usuario } \\ \text { Forma } & \text { Forma } & \text { Uso } \\ \text { Función } & \text { Función } & \\ \text { Posibilidad } & \text { Posibilidad } & \\ \text { Emulación } \rightarrow & \text { Simulación } \rightarrow & \text { Significación }\end{array}$


Como lo expuse inicialmente, el diseño es una actividad que está determinada por la planificación de ciertas experiencias de uso; esa es su razón de ser e instituye su cualidad más representativa. El diseño se define por su propósito fundamental: producir experiencias esperadas y, como disciplina, ha consolidado un marco conceptual que explica sus procesos y condiciones de aplicación en el mundo de la vida cotidiana. La robótica social, de igual manera, es un campo interdisciplinario que incluye el diseño para desarrollar interacciones eficaces con máquinas de simulación social. La experiencia de uso constituye, pues, el gran propósito común del diseño y la robótica. Así que antes de pasar a describir con detenimiento qué es el diseño de experiencias, veamos cuáles son las más importantes características de vivencia planificada en los procesos de diseño de robots sociales.

\section{Lo estético en las vivencias esperadas: realismo y verosimilitud de la simulación}

El robot social humanoide asistencial es un objeto que detona en el sujeto de experiencias diversos estados mentales, cuyo principal carácter es la naturaleza de la respuesta. Los procesos que se dan en la cognición del usuario tienen unas valoraciones específicas basadas, pues, en el efecto. Desde una perspectiva cognitiva, el robot produce unos estímulos sensoriales ante los cuales el usuario reacciona con determinados estados mentales; representaciones basadas en imágenes combinadas con emociones que se articulan en la percepción como acto de consciencia. Desde una perspectiva estética, el sujeto reaccionará con un efecto de aceptación o rechazo, o desde un punto de vista simbólico, con un efecto de valoración conceptual. La cuestión es que las reacciones del usuario se pueden caracterizar y categorizar según las cualidades de los efectos.

Según lo que he desarrollado en páginas anteriores, se puede concluir que la gran mayoría de efectos esperados en un paciente de la tercera edad giran en torno al sentimiento. Es decir, que el sustento de toda percepción humana es necesariamente emocional y, dependiendo de los niveles de emotividad, se pueden estimular experiencias de aprendizaje de mayor o menor eficacia (Damasio, 2007). De ahí la importancia de la exploración de emociones sintéticas en inteligencia artificial o la preocupación de los diseñadores por no "caer" en el "valle inquietante". El aspecto emocional y, en un nivel más complejo, el aspecto sentimental de la experiencia, es un asunto de relevancia estética. La estética pues, es el eje central para iniciar la caracterización y categorización de los efectos en el sujeto de experiencias, y se manifiesta en cada uno de los recursos discursivos del desarrollo de robots sociales:

- En el proceso de diseño, lo estético ha sido el criterio fundamental que ha conducido la decisión de emular al ser humano; el nivel de familiaridad es condicionante natural de aceptación.

- En la valoración principal del producto final, lo estético determina los criterios de simulación; pues el nivel de semejanza, como otra manifestación de lo familiar, motiva la impresión de realidad y, por lo tanto, la verosimilitud de la experiencia; de ahí que se posibilite la eficacia de la sustitución. 
- Y, finalmente, en la experiencia de uso, lo estético también es la base de los procesos de asignación de sentido que el usuario realiza, porque las vivencias que él evoca han sido afirmadas por grados de intensidad emocional que las han constituido en vivencias altamente significativas.

La estética es un concepto demasiado complejo como para ser abordado en este escrito, así que solamente indicaré la perspectiva epistemológica en la cual estoy afiliado. Considero que es válido suponer que en los procesos de aceptación o rechazo mediante los cuales el ser humano (como ser consciente) valora las experiencias, hay implicaciones del gusto que surgen de una predisposición biológica fusionados con los que se aprenden en las vivencias de la cultura a través del arte y la expresión plástica. Así pues, me identifico con la postura de Jacques Rancière $(2012)^{16}$, cuando se refiere a lo estético como un asunto de sensibilidad (sensorium) derivada de ambas condiciones: la natural y la cultural. La capacidad estética del ser humano es un mecanismo perceptivo que permite valorar las experiencias como agradables o desagradables, con base en las emociones, y se construye socialmente sobre el fundamento de nuestra herencia biológica. Las experiencias cotidianas, por lo tanto, siempre son estéticas y condicionan los procesos de aprendizaje social. El anciano experimentará sentimientos de confianza, seguridad o familiaridad, ante una manifestación conductual aparentemente emotiva del robot, como su amabilidad, timidez o alegría. Para que la simulación del androide sea exitosa, debe producir un óptimo efecto de realismo y verosimilitud en el paciente, haciéndole creer que, efectivamente, se involucra en una relación intersubjetiva. Como ya lo había mencionado, la creencia del sujeto de estar interactuando con otro sujeto (otro ser dotado de consciencia) es uno de los desafíos superados del test de Turing. Aunque el anciano es consciente de que su interlocutor no es realmente un ser inteligente, él se dispone a creer en la simulación, dado que el robot efectivamente interactúa con él de manera eficaz, respondiendo preguntas y brindándole información con aparente emotividad; es decir, se le impone "la estructura ontológica" del androide. Esta breve renuncia al estatus de autenticidad del autómata es lo que Alfred Schutz denomina un "salto de un ámbito de realidad con estructura finita de sentido a otro” (2009, p.189), semejante al que vivenciamos cuando vemos una película y nos sumergimos voluntariamente en su relato dramático. Inspirado en Aristóteles, Christian Metz ha expresado, a propósito del sofisticado mecanismo del cine como generador de una "impresión de realidad" mayor a la de la fotografía, que lo verosímil es "el conjunto de lo que es posible a ojos de la opinión común (...). Lo verosímil se define respecto a discursos ya pronunciados" (2002, p.254). Impresión de realidad y apariencia de verdad aparecen aquí como sinónimos y con frecuencia así lo han hecho diversos autores. En adelante, intentaré referirme a la apariencia de lo real (lo existente) como realista y a la apariencia de lo verdadero (lo cierto) como verosímil, intentando diferenciar sutilmente ambas condiciones. Considero válido dar por presupuesto que la realidad alude un estatus de autenticidad de las cosas existentes en el mundo de la vida, mientras que la verdad atañe a un principio de certeza de los hechos y las acciones. Ambas, por supuesto, se relacionan y afectan mutuamente. De 
esta relación da cuenta el lenguaje cuando se emplea bajo una función informativa, es decir, cuando se expresa a propósito de las cosas y los hechos del mundo de la vida. Los sustantivos se refieren a las cosas, los verbos a las acciones y los adjetivos a las cualidades. Los sustantivos relacionan los contenidos de los actos intencionales, por lo tanto, presentan una condición de existencia en la realidad o en la fantasía. Por ejemplo, "Manu" es un sustantivo que alude al apellido de un hombre que existe en el mundo físico. Igualmente, "Argentina” es el nombre de un país, la "esperanza" el nombre de un sentimiento. Los tres casos corresponden a cosas concretas o abstractas que existen en el mundo real. Mientras que "Gregorio Samsa", "Macondo” o "cúnico" son cosas que no existen sino en el mundo de la fantasía. Por otra parte, tanto los verbos como los adjetivos son valorados en términos de la certeza o la falsedad; incluso respecto a la verdad de un relato de ficción. Alexander Manu es un reconocido autor que trata temas sobre diseño: cierto. Argentina está ubicado en el continente Europeo: falso. La esperanza es lo último que se pierde: puede ser verdadero o falso... ¿Cómo saberlo?. Respecto a las cosas que se enuncian provenientes del mundo de la fantasía; La Metamorfosis nos muestra a Gregorio Samsa entusiasmado por la vida: falso. Macondo es un pueblo humilde donde creció la dinastía de los Buendía: cierto. El Chapulín Colorado suele decir: "Calma, calma, que no panda el cúnico" justo antes de decir: “mis antenitas de bilín están detectando la presencia del enemigo”: cierto.Y podría presentar más ejemplos de sustantivos comunes y pronombres que en el contexto de enunciación, tendrían que ser valorados según sus condiciones de realidad y verdad, como por ejemplo: "Tú, mujer inocente, eres la culpable de mis desvelos".

En conclusión, los efectos fundamentales que espera producir una estrategia de diseño experiencial, son el realismo y la verosimilitud; posibilitados gracias a un sistema de simulación. Así como el cine une la condición de simulación de la forma de la imagen fotográfica y la simulación del volumen de la imagen en movimiento, el robot social simula forma, movimiento y, además, racionalidad interactiva, mediante acciones autónomas ejecutadas de manera pertinente, en diversos contextos.

\section{El diseño de experiencias}

"Sólo vemos lo que conocemos", aquella célebre cita de Goethe, es una expresión que abre el camino de la comprensión acerca de los procesos del aprendizaje cognitivo. La relación entre conocer y saber se ha reformulado más recientemente en expresiones de teóricos de la imagen como Ernst Gombrich o Bruno Munnari, quienes han validado el aforismo: vemos lo que sabemos. "Ver" no sólo se refiere a la experiencia de la imagen que opera nuestra inteligencia visual, sino a la experiencia perceptiva ante cualquier estado de cosas del mundo: "Hey, ¿viste cómo está de interesante el tema de la obra?" o "Veo que estás pasando por una situación muy difícil”. De nuestro sistema sensorial, es el sentido que más información le envía al cerebro ( $>80 \%$ ) y el que facilita una mejor comprensión en estrategias pedagógicas. Esa es seguramente la razón por la cual nos referimos como "ver" al "darnos cuenta" del mundo, pues se refiere a los procesos de notificación del mundo y las múltiples acciones intersubjetivas, 
mediatizadas y matizadas por nuestros sentidos. El conocer es un proceso que alude a la experiencia directa con el mundo físico: “¿No conoces la catedral de San Pedro?”, "Has conocido por fín el amor..." "Sabes qué es el amor, pero no lo conoces”; "Sé que algo no anda bien, pero no sé qué". Lo mismo acerca de la Catedral de San Pedro: "Sé cuál es, pero no la conozco". O al contrario: "Conozco al tipo que me dices, pero no sé quien es...” Son dos acciones diferentes, a veces muy bien emparentadas. La relación entre el sujeto y el mundo se construye con base en estas dos maneras de "darse cuenta", y de manera compleja y difusa se permean mutuamente. Primero: sabemos algo por medio de lo que conocemos (cognitivamente), y, segundo: conocemos a través de lo que sabemos (epistemológicamente). Pues bien, el mundo no es algo que aparece ante nosotros como creemos. Hemos aprendido a ver el mundo y a creer que es de cierta manera porque nos hemos acostumbrado a verlo así, con base en procesos que integran la predisposición biológica y la disposición cultural. Como en el test de Rorscharch o en los fenómenos de pareidolia, vemos a través de los lentes de nuestro pensamiento. Cuando vemos, realizamos intrincados procesos de transformación de sensaciones a percepciones y a partir de ahí a concepciones. Las descripciones que realicen centenares de testigos de un mismo hecho, seguramente diferirán en muchos aspectos; no sólo variarán los colores, las formas y las valoraciones emotivas, sino las estructuras relacionales entre ellas. Por esta razón, el acto de ver es, sólo en ese nivel tan básico de percepción, una interpretación. En el complejo proceso de la visión se producen tres tipos de imágenes ante una explosiva manifestación de estímulos lumínicos, constituidos por fotones que se desplazan a determinadas longitudes de onda. La imagen retiniana (proyectada en la parte posterior del ojo de manera invertida) es a su vez recibida por los conos y bastones del sistema ocular y transportada hasta el córtex cerebral, en donde se produce la imagen mental. Esta imagen sólo adquiere coherencia perceptiva en la medida en que nuestra mente le de cierta forma, de acuerdo con un cuantioso archivo visual que le permite "re"conocerla y así, cada uno verá lo que sabe.

\section{¿Diseñar la experiencia?}

El Diseño de experiencias es una noción que ha constituido un sentido relativamente nuevo dentro del estudio del diseño en el siglo XXI. El término hace explícita la función primordial del diseño en general: posibilitar una determinada experiencia mediatizada ${ }^{17}$. Como ya lo había observado al comienzo de este capítulo, a diferencia del diseño gráfico, el diseño visual o el diseño industrial, no se instituyen en la cualidad del proceso: medio físico (gráfico), medio sensorial (visual) o mediaciones productivas (industrial), sino de un fin: la experiencia. Es una denominación polémica, por supuesto, porque no sólo emplea la condición del efecto (la experiencia) como una cualidad que debería aludir al objeto (soporte de la información), sino que es absolutamente genérico: la experiencia es un estado mental que produce un usuario receptor ante un objeto cargado de información. 
Nathan Shedroff (2009) considera el diseño de experiencias como una categoría complementaria al diseño de información, al diseño de interfaces, al diseño de interacción y al diseño sensorial, clasificación que se puede discernir del proceso cognitivo: la información como contenido, la interfaz como soporte, la interacción como vínculo entre el sujeto y el objeto, la sensorialidad como medio de recepción y la experiencia como efecto. Por otra parte, el autor enmarca el diseño de experiencias como campo transdisciplinar en el cual se aborda la preparación de ambientes con el propósito de crear experiencias altamente significativas, según los propósitos comunicacionales del caso (didácticos, persuasivos o de entretenimiento). Se refiere, esencialmente, a la generación de multi-estimulaciones que potencian la relación entre sujetos y sistemas objetuales, generando en el usuario mayores niveles de atención y carga emocional.

El diseño es anticipación y planeación. Según Guillermo González Ruiz "Diseño no es la expresión final de una forma visible, sino el proceso de creación y elaboración por medio del cual el diseñador traduce un propósito en una forma. La palabra diseño es un anglicismo: "design"significa "plan mental, proyecto, programa"según el diccionario de la Academia de Oxford. (...) Lo que define la idea de diseño es el hecho de que las formas resultantes surgen de un plan, de un programa, de una estrategia de abordaje”(1994, p.121). La proyección es la principal característica del diseño; es la cualidad que lo define y que establece la coherencia entre medios y fines. El énfasis que se debe hacer en el desarrollo de una configuración tiene como propósito brindar mayores garantías de un resultado final que cumpla adecuadamente con las necesidades diagnosticadas de un grupo de usuarios. Además del proceso proyectual, como aspecto clave denominador del diseño, se debe considerar el propósito comunicacional. El diseño gráfico o el diseño visual, por ejemplo, presentan diferencias terminológicas superficiales que se disuelven cuando se recuerda que la función primordial es comunicativa en ambos casos. El primero, hace referencia a las características bidimensionales del soporte mediático (prensa, cartel, multimedia o televisión) y el segundo, a las características de un sistema que requiera "ser visto", lo cual incluye la tridimensionalidad y la funcionalidad del espacio. Pero si se tiene presente que el fin es comunicar, lo "visual" puede ser tan restrictivo como lo "gráfico", pues la comunicación involucra la integralidad sensorial, en especial la información auditiva y táctil. De ahí que un proyecto de diseño de información para ciegos sea pertinente al diseño gráfico y no al diseño visual. Esta discusión es, por supuesto, bizantina... El único propósito de expresar estos argumentos es relativizar cada denominación y alinearse con lo que más convenientemente lo denomina Jorge Frascara como diseño de comunicaciones (1996). En cuanto al diseño industrial, es necesario preguntarse: ¿Es realmente un diseño de comunicaciones?... No, en esencia. La función primordial del diseño de objetos es el uso práctico, pero evidentemente, la función comunicativa del objeto es muy importante. El objeto debe ser funcional, tanto en sus condiciones prácticas de uso como en sus condiciones informativas. La comunicación no es, pues, determinante en el diseño objetual, pero definitivamente el diseño de experiencias necesita del diseño industrial para el desarrollo de sistemas ergonómicos e integrales. 
Habiendo disuelto, con cierta levedad, las sólidas y elevadas murallas que separan los tres diseños más pertinentes para establecer la noción de diseño de comunicaciones, es apropiada la categorización que realiza Bruce Brown sobre las tres funciones de la comunicación visual: información, identificación y persuasión ${ }^{18}$ (González, 1994). Esta triada tiene la virtud de sintetizar, de manera representativa, las tres grandes áreas de acción del diseño. El diseño de información (categoría con la que coinciden Frascara y Shedroff) se refiere a todos los procesos del diseño en los que se deben transmitir con claridad y eficacia información descriptiva con máxima objetividad. Este punto también estaría incluido en el Diseño para la educación de Frascara, pues los procesos didácticos deben ser absolutamente excelsos y enfocados a propiciar acciones prácticas concretas. Según Brown, la información implica valores funcionales (entender para poder hacer). Como su fin es básicamente explicar el funcionamiento de un artefacto, un servicio, un proceso, un lugar o el esclarecimiento de un suceso, el diseño de información o gráfica didáctica (Costa, 1987) se especializa en transformar contenidos informativos rígidos en flexibles y amigables para su fácil comprensión; ambienta y posibilita que contenidos complicados se vuelvan sencillos. No involucra la seducción porque, a diferencia del diseño persuasivo, no busca convencer ni ser memorable para no opacar la transmisión de la información, que es su objetivo primordial. Tampoco es pregnante, pues su objetivo fundamental es contribuir a que la información sea central y pueda comprenderse rápidamente, cuando el usuario lo requiera. En esta función se pueden ubicar infografías, manuales de uso, cartillas, interactivos didácticos, instructivos, mapas de recorridos de lugares, gráficos noticiosos o sistemas de información señalética. El diseño editorial y el diseño multimedial, no son propiamente infográficos, pero estarían incluidos debido al procesamiento de grandes y complicados contenidos de datos que deben expresarse en forma clara y fluida.

\section{El diseño de identidad tiene que ver con los} procesos de programación de identidad visual; la creación de identificadores gráficos (logotipos + símbolos), logotipos (palabra diseñada), símbolos gráficos o imagotipos (Moliné, 2000) y emblemas o mascotas representativas de una entidad. Esta orientación del diseño instituye valores neutros para la construcción de la identidad visual y valores persuasivos para proyectarla como imagen reconocible. Por lo tanto, cumple con una función racional-funcional en la construcción de identidad y con una función racional-emocional en la carga pregnante y vocativa de la imagen. Chaves y Beluccia (2003 expresan que la identidad es lo que define a alguien, sus características tangibles e intangibles que lo diferencian y designan
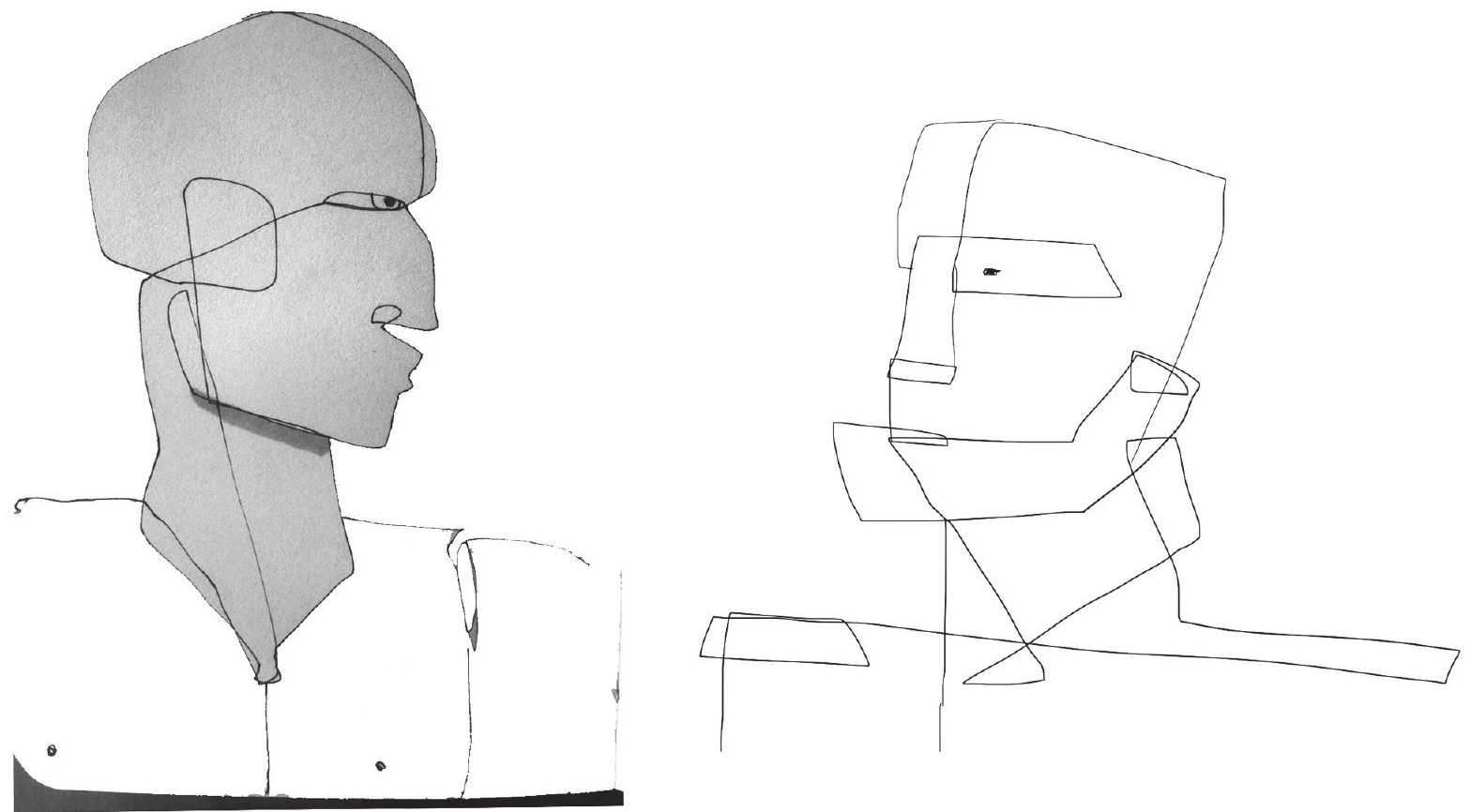
(función sígnica). La imagen (externa) es la proyección de esa identidad (interna). Identidad e imagen deben ser visibilizadas y recordadas por un público amplio que pueda diferenciar la marca. No es funcional en el sentido de que no explica el funcionamiento de algo, de modo que no es, pues, un recurso demostrativo sino mostrativo. La identidad visual expone gráfica y objetualmente cualidades materiales e inmateriales. Cumple una función simbólica que depende de un aprendizaje (arbitrariedad) basado en las características denotativas y connotativas del signo visual.

El diseño persuasivo aborda todo lo relacionado con la articulación de discursos visuales afectivos propios del medio publicitario, en donde la retórica de la imagen ha sido mayormente aprovechada y desarrollada. Los valores que imperan en esta función son absolutamente emocionales y a través de ellos pretende impactar al público para lograr seducirlo. El efecto que procura la persuasión es complejo y ambicioso, pues se espera que el mensaje sea recibido, comprendido y, como propósito fundamental, que active su motivación para actuar de cierta manera prevista (comprar, ir, recordar o cambiar de opinión).

Así pues, todo diseño procura una experiencia. Enmarcado en dinámicas comunicativas, cualquier diseño estará enfocado en generar experiencias informativas y significativas, de modo que es pertinente preguntarse: ¿Por qué concebir una nueva denominación a una especialidad del diseño basada en una cualidad que es común a todos los diseños?...Y aún más necesario es preguntarse: ¿Se puede diseñar una experiencia?

\section{Experiencia y vivencia}

Así como la concepción de diseño no se refiere a una actividad nueva, pues a lo largo de la historia se ha profesado en múltiples ocasiones, las estrategias comunicativas para producir experiencias significativas también son milenarias. El diseño de experiencias se ha manifestado desde las narraciones orales de las primeras colectividades en los que el orador, dotado de excepcionales habilidades creativas e ilocutivas, lograba la inmersión de su auditorio en historias que suscitaban grandes emociones. Mucho tiempo después, en la antigua Grecia, los poetas, actores y relatores de historias persuadían con base en la retórica; "el arte del buen decir", gracias a la cual envolvían al auditorio llenándolo de pasión por la acción: “Cuando Cicerón finalizaba su discurso, el pueblo decía: "Qué bien ha hablado”... pero cuando hablaba Demóstenes, el pueblo gritaba: “¡Marchemos contra el enemigo!”” (Moliné, 2000). Dos milenios más tarde, en la Europa barroca, en pleno apogeo de la Reforma protestante, las argucias corporativas de la Iglesia Católica confeccionaron la Contrarreforma, con base en la implementación de estrategias discursivas que recuperaban eficazmente a muchos de los feligreses "confundidos". El inmenso poder simbólico de los objetos y entornos arquitectónicos (externos e internos), entre otras ingeniosas articulaciones sistémicas que involucraban la escultura, la pintura, el vestuario y la oratoria (Huyghé, 1977), conducían a la oveja "extraviada" de nuevo al redil bajo la extenuante opresión de la mirada de Dios. 
Desde una perspectiva histórica, se hace evidente que efectivamente sí se pueden diseñar experiencias. A diferencia del diseño de objetos o de información, el diseño de experiencias incorpora en su expresión la complejidad del nivel del efecto. El calificativo experiencial, alude al poder de cierta experiencia, a la fuerza de la significación que procure un objeto o sistema en la construcción de un extraordinario sentido vivencial. El diseño de experiencias tiene el propósito de producir grandes vivencias.

Hans Georg Gadamer, en Verdad y método, realiza un juicioso rastreo histórico de la noción, que permite diferenciar claramente (y de manera necesaria) experiencia de vivencia: "Lo vivido (das Erlebte) es siempre lo vivido por uno mismo. Pero al mismo tiempo la forma das Erlebte se emplea también en el sentido de designar el contenido permanente de lo que ha sido vivido. Este contenido es como un resultado o efecto que ha ganado permanencia, peso y significado respecto a los otros aspectos efímeros del vivir. (...) Aquello que puede ser denominado vivencia se constituye en el recuerdo. Nos referimos con esto al contenido de significado permanente que posee una experiencia para aquel que la ha vivido" (2007, p. 97). Podría expresarse también así: la experiencia es el resultado de una condición de recepción de estimulación sensorial, mientras que la vivencia alude a una cierta experiencia cualificada, dotada de mayor impacto, sentido y conciencia del self; almacenamos recuerdos de nuestras vivencias, no de simples experiencias.

Nathan Shedroff ha desarrollado a través de cuatro publicaciones ${ }^{19}$ lo que él mismo llama: "un manifiesto acerca del diseño de experiencias", que resulta ser un completo estudio de la noción. Así pues, ha argumentado por qué la experiencia se puede diseñar: "Mientras todo, técnicamente, es una experiencia de alguna clase, hay algo importante y especial en muchas experiencias que suscitan ricas discusiones. En particular, los elementos que contribuyen a producir experiencias superiores son conocibles y reproducibles, lo cual las hace diseñables". Shedroff considera que "las experiencias tienen seis dimensiones: significancia, amplitud, intensidad, duración, gatillos (sensoriales y cognitivos) e interacción” (2009). Estas seis dimensiones son, precisamente, los principios de diseño que él propone como condiciones posibilitadoras de experiencias sobresalientes para un usuario:

1. - La significancia es la dimensión del valor que se le asigna al sistema en términos de sentido, atribuyéndole un nivel de status y matiz emocional.

2. - La amplitud se relaciona con las características del sistema; su disposición para el público de manera consistente en cuanto a accesibilidad. 3. - La intensidad es el nivel de correspondencia que tiene para el usuario, acorde a sus hábitos, y que logra generar en él un compromiso.

4. - La duración es el nivel de inmersión que puede producir gracias a sus características envolventes.

5. - Los gatillos sensoriales y cognitivos son los estímulos que se direccionan a los cinco sentidos y la articulación de conceptos y símbolos coherentes según el público.

6. - Finalmente, la interacción es el proceso de intercambio del usuario con el sistema, en cuyo nivel más alto recibe información de manera activa. 
En cuanto al proceso que se produce entre el sujeto y el objeto (o sistema objetual), el autor ha propuesto tres grandes fases progresivas: atracción, compromiso y conclusión. "La atracción es necesaria para iniciar la experiencia. Puede ser cognitiva, visual, auditiva o una señal cualquiera dirigida a nuestros sentidos". "El compromiso es la experiencia misma. Necesita ser suficientemente distinta a lo que rodea el entorno de la experiencia para mantener la atención de la audiencia o el usuario, así como ser cognitivamente importante (o relevante) para continuar la experiencia”. Y "la conclusión puede suceder de varias maneras, pero debe proveer algún tipo de resolución, ya sea a través del significado, la historia o contexto, o la actividad que haga disfrutable y satisfactoria la experiencia, de alguna manera". "El diseño de experiencias es una aproximación a la creación de experiencias exitosas para la gente en cualquier medio. Este abordaje incluye considerar y diseñar en las tres dimensiones espaciales, los cinco sentidos del cuerpo y la interactividad, ya sea un valor de consumo, un significado personal y un contexto emocional. El diseño de experiencias no consiste solamente en el diseño de páginas web, de otro medio interactivo o de contenido digital en pantalla... Puede desarrollarse en cualquier medio, incluyendo el espacio e instalaciones en entornos, impresos, productos, servicios, imágenes y sonidos televisados, presentaciones y eventos en vivo, medios digitales y en línea, etc.” (Shedroff, 2009, p.6).

Como apoyo a los sólidos planteamientos de Shedroff, Pere Rosales (2010), catedrático español y comunicador estratégico, ha desarrollado lo que él denominó: Manifiesto inusual por el diseño de experiencias, en el cual propone un enfoque complementario desde la perspectiva del diseño emocional. Este autor propone "tres características claves" para el desarrollo de sistemas emocionales: simplicidad, flujo y deseo. La simplicidad, está básicamente relacionada con la tradicional noción de amigabilidad; que procura la facilidad de uso del sistema. El término flujo se refiere al mismo efecto que Shedroff llama inmersión, dentro de la dimensión de la duración. Y el deseo, referido a lo que se debe generar en el usuario, gracias a los atributos formales y simbólicos del sistema, que lo vinculan como en una relación dialógica.

Hoy en día las estrategias de experiencia son bastante comunes y minuciosamente aprovechadas por las corporaciones a través de onerosas dinámicas de mercadeo estratégico para estimular nexos emocionales con los productos y sus marcas. Igualmente, el diseño de experiencias no está relacionado solo con las dinámicas de usabilidad digital interactiva, como los videojuegos, la multimedia, la internet, los dispositivos de comunicación portátiles o los cajeros automáticos, pues como lo expresa Shedroff: "el diseño de experiencias puede desarrollarse en cualquier medio" porque "toda experiencia es importante". Por lo tanto, la robótica social asistencial no está excluída de este extenso dominio proyectual y, como lo he expuesto durante todo el texto, robótica social y diseño experiencias coinciden en muchos aspectos conceptuales y metodológicos, siendo los más relevantes los relacionados con la expectativa de experiencias en pacientes de la tercera edad, mediante un sofisticado sistema de simulación artificial, y bajo los efectos esperados de realismo y verosimilitud. 


\section{Nota}

${ }^{1}$ Fingimiento. Parecer ser algo que no se es.

${ }^{2}$ El término está específicamente tomado del marco teórico de Alfred Schutz sobre los sentidos en el mundo de la vida.

${ }^{3}$ Una relación dual, semejante a la empleada por Ferdinad De Saussure respecto a la relación entre significante y significado, en el signo, o los conceptos de forma y contenido en Hjemvslev.

${ }^{4}$ Según Mestres y Vives-Rego (2011), la robótica se ha inspirado en tres grandes categorías funcionales del ser humano: mecánicas, cognitivas y decisorias.

${ }^{5}$ Curiosamente, a esta corriente se le ha denominado funcionalismo, porque permite comprender y explicar los procesos biológicos como análogos a los artificiales y viceversa (Mattelart, 1997).

${ }^{6}$ Según Antonio Damasio, el ser humano necesita de los sentimientos para razonar eficazmente. El establecimiento de estructuras de sentimiento (mecanismo de valoración emocional), genera procesos de adaptación emocional como forma de aprendizaje, lo cual favorece los procesos de toma de decisión adecuada.

${ }^{7}$ La simulación de aprendizaje de un robot social se puede comprender en esencia, como la modulación dinámica de dos grandes esquemas: la arquitectura de programación previa y la captación de contextos de recepción de estímulos. Estos dos esquemas dialogan y son procesados en una relación de "padres" a "hijos", mediante valoraciones que realiza el sistema de manera jerárquica, dando origen a nuevos comandos que se incorporan también bajo criterios de jerarquización. En la hipótesis del sistema de símbolos físicos, John McCarthy declaró: “Todo aspecto de aprendizaje o cualquier otra característica de inteligencia puede ser definido de forma tan precisa que puede construirse una máquina para simularlo".

8 "El término propiocepción aparece fundamentalmente en las investigaciones de psicofísica. Es el sentido que nos informa de la posición, orientación y rotación del cuerpo en el espacio, y de la posición y los movimientos de los distintos miembros del cuerpo, merced a las sensaciones cinestésicas (o sensaciones de movimiento); los receptores o terminaciones nerviosas de este sentido están localizados en los músculos, tendones, articulaciones y oído interno". [http: / / www.e-torredebabel. com/Psicologia/Vocabulario/Psicologia-Vocabulario.htm]: Diccionario de Psicología (Javier Echegoyén Olleta).

${ }^{9}$ Las emociones son prefijadas y actúan esencialmente como perturbaciones; interrumpen el proceso de deliberación en curso. Dichos contenidos son de cuatro clases: representacionales; emociones formalizadas como conceptos, no representacionales; emociones modeladas como señales de alarma, captaciones reactivas en tiempo real; mecanismos de vigilancia e interrupción y disponibles sin interrupción; emociones como motivaciones. Estas últimas son las que promueven mayor autonomía en el robot porque no dependen de la programación ni de la interacción in situ, sino de una especie de rememoración de información guardada.

${ }^{10}$ Breazeal ha propuesto tres condiciones básicas en el diseño de robots sociales; la expectativa del usuario frente al robot debe ser entretenida, atractiva y simple.

${ }^{11}$ De las investigaciones sobre medios de comunicación masiva surgieron varios modelos sobre la comunicación social, desarrollados a través de estudios funcionalistas adoptados por escuelas sociológicas y sicológicas. En la primera mitad del siglo XX los enfoques cuantitativos de la Mass Comunication Research inaugurados por la Escuela de Chicago, realizaron rigurosos estudios de audiencias, con el propósito de contribuir a la gestión gubernamental de las opiniones a través de la vigilancia, control y modelamiento de las audiencias. Estos son algunos modelos:

\section{A. El modelo de la aguja hipodérmica}

Desestimado por su unidireccionalidad, finalmente no pasa de moda, porque es el que mejor describe una gran cantidad de procesos de información en la actualidad: Emisor -> Mensaje -> Receptor No promueve la retroalimentación ni la estrategia de análisis de la audiencia. Tampoco expone la importancia del medio, que por ser portador del mensaje lo afecta, ni del código, que es la estructura de convenciones linguísticas que deben ser comunes entre el emisor y el receptor para que haya entendimiento. 


\section{B. El modelo de Shannon/Weaver (1947)}

Es el modelo representativo de la Teoría de la información, dentro de la línea cibernética del estudio de los procesos de transmisión de información. No sólo se refiere a procesos comunicativos entre personas, sino a cualquier tipo de proceso instrumental como la medición de la temperatura o una grabación audiofónica. En el gráfico aparece un establecimiento pertinente del elemento Fuente, diferenciado de Transmisor y del de Receptor de Destino. Al diferenciar con precisión estos dos momentos de la polaridad comunicativa (que es lo pertinente), se reconoce la importancia de las dos instancias en la emisión y las dos en la recepción. Implica además la naturaleza de la codificación, fundamental para la función del diseñador.

Fuente - Transmisor ----------- Señal ----------- Receptor - Destino

ElTransmisor equivaldría al codificador, pues es el Receptor quien, consecuentemente, descodifica la señal. Presenta, sin embargo, una ausencia importante todavía: el medio.

C. El modelo de Laswell (1948)

Con base en el modelo de Shannon/Weaver, Harold Laswell elaboró un esquema de aplicación para procesos comunicativos en los que tuvo en cuenta el carácter de los elementos, exponiendo aspectos estratégicos primordiales como la intencionalidad en el emisor y la expectativa frente a los receptores.

$$
\begin{array}{lrrr}
\text { Emisor } & \text { Mensaje } & -1 & \text { Receptor } \\
\text { (quién dice) } & \text { (qué dice) } & \text { (a través de cual canal) } & \text { (a quién - qué efecto) }
\end{array}
$$

D. El modelo de Brembeck / Howell (1976)

Es uno de los que mejor representa el proceso de interacción humana, debido a la importancia que le asigna a la función de retroalimentación que debería tener toda gestión comunicacional. Está constituido de la siguiente forma: Fuente /Emisor - Objetivos - Análisis de audiencia - Mensaje - Canal/ Medio - Receptor

En el receptor se da un proceso de Percepción, Decodificación, Activación y Retroalimentación. El estudio de la respuesta en el Receptor, a través de estos cuatro pasos, proporciona la información necesaria para ajustar los objetivos en el siguiente proceso. De esta manera el modelo articula sistemáticamente la retroalimentación y promueve un diálogo con las audiencias. Por lo tanto, la síntesis de los aspectos mínimos necesarios de los modelos expuestos anteriormente, que corresponden con los procesos comunicativos, sería la siguiente:

Remitente - Emisor

(Codificadores que establecen objetivos según el análisis de audiencias)

Mensaje/Medio

Receptor - Destinatario

(Perceptores y Decodificadores, Activados motivacionalmente, Retroalimentadores)

${ }^{12}$ Una de las mayores evoluciones que ha tenido la robótica es la reproducción de voces más naturales (más semejantes al ser humano) en dos aspectos: emotividad (fluidas, con variaciones de entonación, velocidad y volumen) e institucionalidad (alusivas a hombres o mujeres que se expresan con un estilo formal de índole corporativa).

${ }^{13}$ Alfred Schutz ha categorizado estos elementos fenoménicos del mundo de la vida cotidiana como tipicidades pre-lingüísticas. 
14 “Si la inteligencia artificial fuera verdadera, todo el mundo debería poder adquirir cualquier capacidad cognitiva a través de la mera ejecución del programa informático que la simula. (...) La computadora opera a través de la manipulación de símbolos. Sus procesos se definen de manera puramente sintáctica, mientras que a mente humana tiene algo más que símbolos no interpretados: asocia significados a ellos"- John Searle (2006, p.118).

${ }^{15}$ El mismo fenómeno ocurre también con las prótesis mecánicas. Los pacientes aprecian más las que reflejan un estilo futurista, metalizado y exhuberante; una cierta orientación contemporánea a apreciar la fusión entre el hombre y la máquina, bajo tendencias estéticas del cyberpunk o steampunk entre otras.

${ }^{16} \mathrm{El}$ sensorium, como facultad del ser humano de sentir frente a las experiencias. Este semtimiento se tiene en un aspecto natural y se obtiene por una construcción de mirada que proviene del aprendizaje cultural.

${ }^{17}$ Entre los estudios que han contribuido a la exploración de la noción se encuentran: D'Hertefelt, Kankainen, Arhippainen, Knapp Bjerén, y Jacon Nielsen como los más sobresalientes.

${ }^{18}$ Se desestimaron las cuatro categorías del diseño de comunicación de Jorge Frascara: Diseño para la educación, diseño para la información, diseño para la persuasión y diseño para la administración, por considerar que no eran adecuadamente representativas en su diferenciación exclusiva.

${ }^{19}$ Experience Design 1, Experience Design 2, Experience Design 3 y Experience Design 1.1 (2009).

\section{Referencias}

Arrabales, R. \& Sanchios de Miguel, A. (2006). La aplicación de modelos de consciencia artificial en los sistemas multiagente. En A. Fernández-Caballero, M.G. Manzano, E. Alonso \& S. Miguel (Eds). Una perspectiva de la inteligencia artificial en su 50 aniversario (pp. 401-412). Albacete: Universidad de Castilla-La Mancha, Departamento de Sistemas Informáticos.

Baylon, Ch. \& Mignot, J. (1996). La comunicación. Madrid: Editorial Cátedra.

Becerra, J.A., Bellas F. y Duro, R.J. (2006) Arquitectura cognitiva para robots autónomos basada en la integración de mecanismos deliberativos y reactivos. En A. Fernández-Caballero, M.G. Manzano, E. Alonso \& S. Miguel (Eds:). Una perspectiva de la inteligencia artificial en su 50 aniversario (pp. 345356). Albacete: Universidad de Castilla-La Mancha, Departamento de Sistemas Informáticos.

Bedia, M.G., Corchado, J.M. y Ostalé, J. (2006) Arquitecturas emocionales en inteligencia artificial. En A. Fernández-Caballero, M.G. Manzano, E. Alonso \& S. Miguel (Eds). Una perspectiva de la inteligencia artificial en su 50 aniversario. (pp. 186-193). Albacete: Universidad de Castilla-La Mancha, Departamento de Sistemas Informáticos.

Breazeal, C.L. (2002). Designing Sociable Robots. Cambridge (MA): Mit Press

Cañas, José María. Matellán, Vicente. De simbólicos vs. subsimbólicos, a los robots etoinspirados. En A. Fernández-Caballero, M.G. Manzano, E. Alonso \& S. Miguel (Eds:). Una perspectiva de la inteligencia artificial en su 50 aniversario (pp. 332-344). Albacete: Universidad de Castilla-La Mancha, Departamento de Sistemas Informáticos.

Chaves, N. \& Belluccia, R. (2003). La marca corporativa: gestión y diseño de símbolos y logotipos. Argentina: Paidós Iberoamérica

Costa, J. (1987). Imagen global: evolución del diseño de identidad. España: Ediciones CEAC

Cross, N. (1999). Métodos de diseño. México: Editorial Limusa.

Cuadros Contreras, R. (2010). Reflexiones sobre alteridad y técnica: la figura del robot humanoide en algunas transposiciones de la literatura al cine. En Revista CS, O(2) (pp. 247-263). ISSN 2011-0324.

Recuperado de: http://www.icesi.edu.co/revistas/index.php/revista_cs/article/view/420.

Damasio, A. (2007). El error de Descartes. Barcelona: Editorial Crítica.

Frascara, J. (2006). El diseño de comunicación. Argentina: Ediciones infinito.

Gadamer, H. G. (2007). Verdad y método. Salamanca: Ediciones Sígueme.

Garrell, A. \& Sanfeliu, A. (2010). La influencia del efecto "Uncanny Valley" en el diseño de un robot social. En International Congress of Design and Innovation of Catalonia. 1st International Congress of Design and Innovation of Catalonia (pp. 84-95). Recuperado de: http://hdl.handle.net/2117/12547 
Gombrich, E. (1999). Meditaciones sobre un caballo de juguete. Madrid: Editorial Debate.

González Ruiz, G. (1994). Estudio de Diseño. Buenos Aires: Emece Editores.

Huyghé, R (1977). El arte y el hombre. Barcelona: Editorial Planeta.

Löbach, B. (1976). Diseño industrial. Barcelona: Editorial Gustavo Gili.

(McLuhan, 1996). Comprender los medios de comunicación. España: Editorial Paidós

Manu, A. (1998). Tooltoys:Tools with an element fo play. Danmark: Dansk Design Center.

Mendizábal, P., León, E., Ruiz, M. \& Alutiz, G. (2013). Una experiencia de innovación colaborativa en tecnología centrada en la persona: la detección emocional y sus posibles contribuciones al apoyo de personas con discapacidad intelectual y del desarrollo. En Revista Española de Discapacidad, I(2) (pp. 119-131). España: Centro Español de documentación sobre discapacidad. Fundación Eguía Careaga. Recuperado en: http: / /hdl.handle.net/1181/4015

Mestres Naval, F. \& Vives-Rego, J. (2011). Precisiones interdisciplinares y conceptuales de los términos cyborg, clon humano y robot. En Revista Ludus Vitalis, vol. XIX, num. 35 (pp. 235-239). México: Centro de Estudios Filosóficos, Políticos y Sociales Vicente Lombardo Toledano.

Mestres Naval, F. \& Vives-Rego, J. (2012). La convivencia con los cyborgs y los robots: consideraciones filosóficas, ético-morales y sociopolíticas. En Revista Ludus Vitalis, vol. XX, num.38 (pp. 215-243). México: Centro de Estudios Filosóficos, Políticos y Sociales Vicente Lombardo Toledano.

Metz, Ch. (2002). Ensayos sobre la significación en el cine. España: Editorial Paidós.

Moliné, M. (2000). La fuerza de la publicidad. España: Mc Graw Hill.

Núñez, P., Bustos, P., Jaramillo, E., Bachiller, P. \& García-Varea, I. (2011). Robots Sociales para la mejora de la calidad de vida de las personas dependientes. En M. Mazo y F.J. Perales (Eds). VI Congreso Iberoamericano de Tecnologías de Apoyo a la Discapacidad IBERDISCAP 2011 Tomo 1 (pp. 94-103). España: Comité organizador IBERDISCAP.

Rancière, J. (2012). El malestar en la estética. Buenos Aires: Editorial Capital Intelectual.

Rosales, P. (2010). Estrategia Digital. España: Grupo Planeta.

Salichs, M., Salichs, E., Encinar, I., Castro-González, A. \& Malfaz, M. (2014). Estudio de escenarios de uso para un robot social asistencial para enfermos de Alzheimer. En Actas de las XXXV Jornadas de Automática, 3-5 de septiembre de,Valencia. ISBN-13: 978-84-697-0589-6. España: Comité Español de Automática de la IFAC.

Schutz, A. \& Luckman, T. (2009). Las estructuras del mundo de la vida. Buenos Aires: Amorrurtu Editores. Searle, J. R. (2006). La mente. Una breve introducción. Colombia: Editorial Norma

Sennet, R. (2012). El artesano. Barcelona: Anagrama.

Shedroff, N. (2009). Experience Design 1.1: a manifesto for the design of experiences. E.U.: Experience Design Books.

Vallverdú, J. (2007). ¿Por qué motivos crearemos máquinas emocionales? En Astrolabio. Revista Internacional de Filosofía. Núm. 5. ISSN 1699-7549 (pp. 44-52).

Recibido: abril 30 / Aprobado: junio 1 de 2015

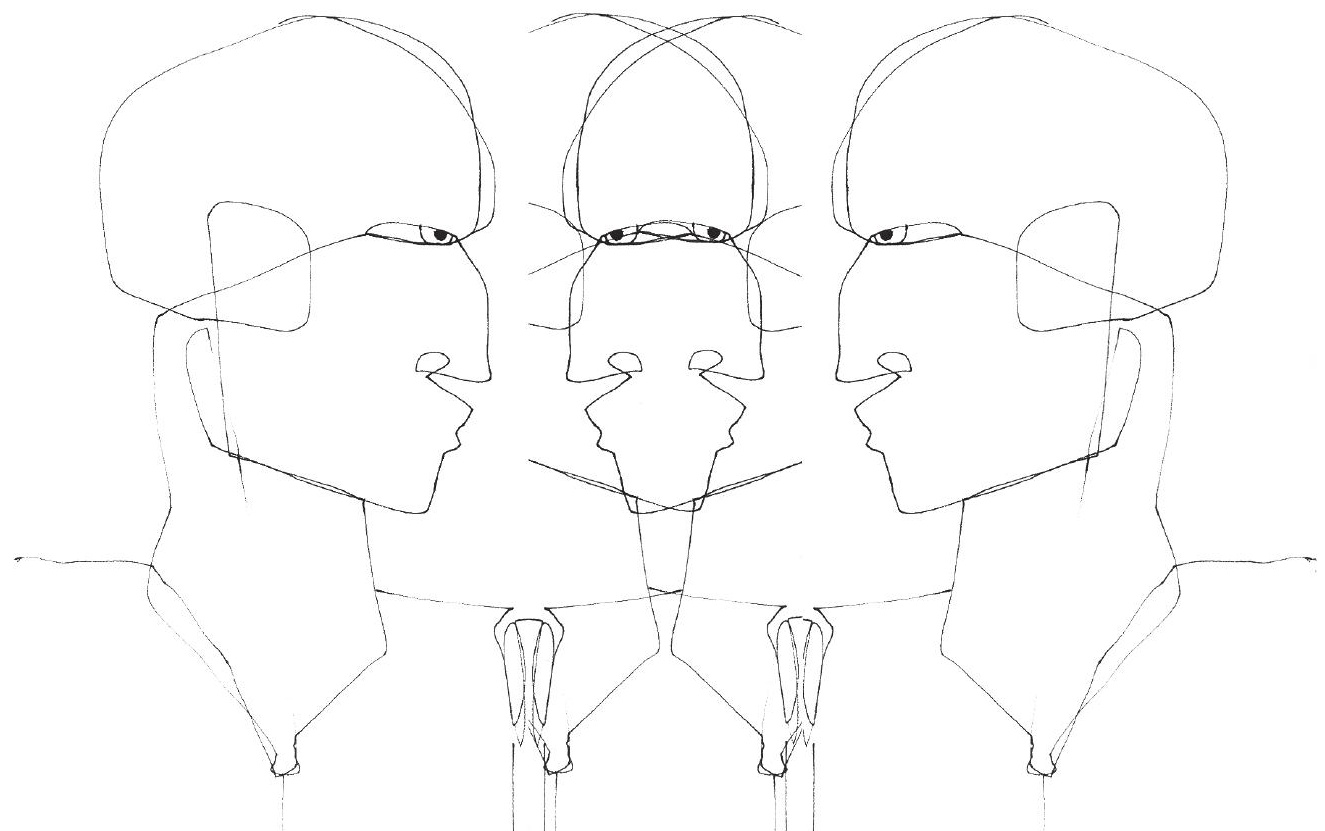

